\title{
Sequencing and comparative genomic analysis of 1227 Felis catus CDNA sequences enriched for developmental, clinical and nutritional phenotypes
}

\author{
Kristopher J Irizarry ${ }^{1,2}$, Sukhaswami B Malladi ${ }^{3}$, Xiangming Gao ${ }^{3}$, Katherine Mitsouras ${ }^{2,4}$, Lynda Melendez ${ }^{3}$, \\ Patricia A Burris ${ }^{3}$, Jeffrey A Brockman ${ }^{3}$ and Samer W Al-Murrani ${ }^{3^{*}}$
}

\begin{abstract}
Background: The feline genome is valuable to the veterinary and model organism genomics communities because the cat is an obligate carnivore and a model for endangered felids. The initial public release of the Felis catus genome assembly provided a framework for investigating the genomic basis of feline biology. However, the entire set of protein coding genes has not been elucidated.

Results: We identified and characterized 1227 protein coding feline sequences, of which 913 map to public sequences and 314 are novel. These sequences have been deposited into NCBI's genbank database and complement public genomic resources by providing additional protein coding sequences that fill in some of the gaps in the feline genome assembly. Through functional and comparative genomic analyses, we gained an understanding of the role of these sequences in feline development, nutrition and health. Specifically, we identified 104 orthologs of human genes associated with Mendelian disorders. We detected negative selection within sequences with gene ontology annotations associated with intracellular trafficking, cytoskeleton and muscle functions. We detected relatively less negative selection on protein sequences encoding extracellular networks, apoptotic pathways and mitochondrial gene ontology annotations. Additionally, we characterized feline cDNA sequences that have mouse orthologs associated with clinical, nutritional and developmental phenotypes. Together, this analysis provides an overview of the value of our cDNA sequences and enhances our understanding of how the feline genome is similar to, and different from other mammalian genomes.

Conclusions: The cDNA sequences reported here expand existing feline genomic resources by providing highquality sequences annotated with comparative genomic information providing functional, clinical, nutritional and orthologous gene information.
\end{abstract}

Keywords: Feline, bioinformatics, comparative genomics, CDNA, annotation, gene ontology, OMIM, ortholog, nutrition, phenotype

\section{Background}

The domestic cat, Felis catus, is a member of the family Felidae and represents the Feliformia branch of the order Carnivora [1]. The domestic cat is an important companion animal and veterinary species. There are roughly 82 million companion cats living in more than 35 million US households [2]. The domestic cat also has

\footnotetext{
* Correspondence: Samer_Al-Murrani@hillspet.com

${ }^{3}$ Pet Hill's Pet Nutrition, Pet Nutrition Center, 1035 NE 43rd Street Topeka, KS 66617, USA

Full list of author information is available at the end of the article
}

substantial value as a model organism for comparative mammalian genomics because it is an obligate carnivore [3], unlike the dog which is an omnivore [4]. Additionally, the domestic cat is an important model organism for Felidae because of its close phylogenetic relationship to the wildcat (Felis silvestris), the sand cat (Felis margarita), the black-footed cat (Felis nigripes) and the jungle cat (Felis chaus). It can also serve as a model for more distantly related felid species including pumas such as the Cheetah (Acinonyx jubatus), lynx species, ocelots $[5,6]$, and members of panthera including the

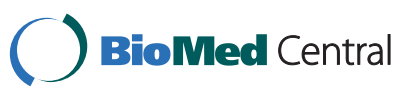

(c) 2012 Irizarry et al; licensee BioMed Central Ltd. This is an Open Access article distributed under the terms of the Creative Commons Attribution License (http://creativecommons.org/licenses/by/2.0), which permits unrestricted use, distribution, and reproduction in any medium, provided the original work is properly cited. 
lion (Panthera leo), the tiger (Panthera tigris), and snow leopard (Uncia uncia) [7]. A major goal of feline genomics is to identify and decode both cat-specific biology as well as conserved mammalian biology. The identification of feline-specific biochemistry and physiology is required in order to better understand the unique nutritional and veterinary needs of cats and to enhance the wellness of domestic cats as well as the health and management of captive felid species.

A number of cat-specific biological adaptations have been described to date. Cats exhibit a variety of evolutionary adaptations thought to be associated with their predatory behaviour and obligate carnivore status. For example, domestic cats exhibit distinct distal forelimb anatomical adaptations associated with predation $[8,9]$, as well as sensory adaptations in both sound perception [10-12] and visual acuity $[13,14]$. At a molecular level, cats exhibit differences in the regulation of sugar transporters [15] resulting in lower liver glucose transporter activity [16] and differences in carbohydrate metabolism compared to omnivores [17]. Because the carnivore diet is relatively high in amino acid content, adult cats maintain blood glucose levels from gluconeogenesis of glucogenic amino acids, lactic acid and glycerol [18]. Compared to omnivorous mammals, in which gluconeogenesis occurs in the post absorptive state, cats exhibit the greatest extent of gluconeogenesis right after a meal during the absorptive state [19].

Amino acid biosynthesis and deficiency has been relatively well studied in domestic cats. Cats have dietary requirements for the amino acids taurine [20], arginine [21], cysteine and, methionine [22]. Arginine deficiency in cats has been associated with rapid onset of hyperammonemia characterized by severe signs of ammonia toxicity [23]. The sulphur containing amino acids cysteine and methionine are normally present in high amounts in animal flesh and are required for normal feline development $[24,25]$. The beta-amino sulfonic acid taurine is required in cats because, unlike many other species which can conjugate bile acids to either glycine or taurine for secretion of bile salts into bile, cats can only use taurine. Unlike dogs, cats have evolved limited capacity to synthesize taurine [26], subsequently, taurine deficiency in cats is associated with abnormal cardiac [27], immune [28], neurological [29], platelet [30], reproductive [31] and retinal [32] dysfunctions. The recent description of the taurine transporter knock out mouse underscores the biological roles of taurine in mammals [33].

Although many aspects of feline-specific biology have been elucidated to date, bioinformatics methods and comparative genomics approaches can provide a mechanism for producing a number of plausible and useful biological hypotheses from feline cDNA sequences.
The 2007 release of the feline genome [34] marked the beginning of the feline genomics era, which was followed by the identification of close to 1 million single nucleotide polymorphisms across cat breeds [35] which further extends the repertoire of genomic tools for investigating the genomic basis of feline phenotypes. In this paper, we describe the sequencing of additional feline cDNA sequences and demonstrate the utility of employing comparative genomics methods to investigate, not only the roles of these cDNA sequences, but the extent to which these feline sequences diverge from other mammalian orthologous sequences.

Our working hypothesis is that conservation among human, mouse, dog and cat orthologs underscores conserved mammalian biology while feline sequence divergence among mammalian orthologs provides potential insight into cat-specific biology. Specifically, we employ a computational comparative gene expression analysis to map the cDNA sequences to anatomical information, developmental timelines, cells and pathology terms. Additionally, we utilize the gene ontology annotation, in combination with measures of synonymous and nonsynonymous differences in orthologous protein sequences, to better understand which of the cDNA sequences are likely to represent conserved mammalian biology and which are more likely to represent felinespecific biology. We organize these results into biological processes, cellular localization and molecular function in order to more easily interpret the results. Finally, we map these feline cDNA sequences to orthologs in other species in order to identify (1) phenotypes, (2) biochemical pathways and (3) human diseases in an attempt to better understand the roles of these cDNA sequences in feline development, nutrition and disease.

\section{Results}

\section{Sequencing and Orthologue Identification}

1227 high quality feline cDNA sequences were identified from a starting set of 3035 cDNA sequences (Figure 1). Total RNA was purified from 21 feline tissues (brain, kidney medulla/cortex, spleen, heart, liver, lung, skeletal muscle, thyroid gland, lymph node, pancreas, adrenal gland, tongue, colon, mammary gland, neonatal thymus, brain and testes) collected from 10 domestic shorthaired cats post-mortem, three cell lines derived from kidney, brain, lung, and 1 tissue pool using standard procedures. The initial set of 3035 cDNA sequences was assembled from the sequencing reads from tissue specific cDNA libraries. These sequences were designated full length because they corresponded to the complete length of assembled sequencing reads. These sequences were translated to produce protein sequences and clustered in nucleotide space and protein space to identify a set of non-redundant full length sequences. The results 


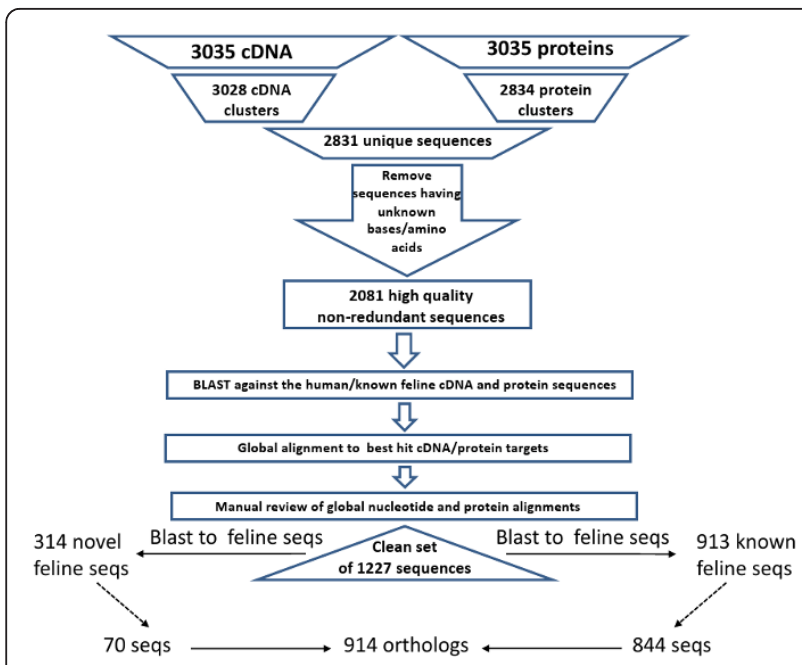

Figure 1 Schematic Representation of Identification of 1227 Feline cDNA Sequences. An initial set of 3035 cDNA sequences were clustered in nucleotide and protein space to identify the longest representative sequence for each cluster. The intersection of the set of cDNA and protein clusters resulted in a set of 2831 cDNA sequence clusters. All sequences within this set that contained N's were removed resulting in a set of 2081 high quality, nonredundant CDNA sequences. These sequences were blasted against the (1) set of ensembl human known cDNA and protein sequences and (2) feline known cDNA and protein sequences. Global alignments were generated for each cDNA blast hit and manually inspected for quality. The final set of 1227 cDNA sequences corresponded to 913 known feline cDNA sequences and 314 novel feline sequences. Blasting to dog, human and mouse sequences identified a total of 914 orthologs, corresponding to 70 novel and 844 known sequences.

of the clustering produced 3028 nucleotide clusters and 2834 protein clusters. The intersection of these two sequence sets was used to produce the final clustered full length sequences, for which there were 2831 sequences. The set of clustered sequences were filtered to remove sequences containing non-nucleotide and non-amino acid letters which resulted in a set of 2081 high quality non-redundant full length sequences.

For the set of 2081 cDNA sequences, the shortest and longest sequences were 353 and 4750 nucleotides respectively. The average nucleotide length was 1349 nucleotides with a standard deviation of 567 nucleotides. The 2081 protein sequence set exhibited a shortest and longest sequence of 41 and 1128 amino acids respectively. The average protein sequence length was 279 amino acids with a standard deviation of 149 amino acids.

This set of sequences was used to blast against the set of known human cDNA and protein sequences to identify the best human match (see Figure 1). Additionally, these 2081 cDNA sequences were blasted against known and $a b$ initio feline cDNA and protein sequences from ensemble [36] to identify sequences for which public feline sequence data exists. Subsequently, these sequences were aligned using a global alignment algorithm to remove sequences for which the best blast hit represented only local homology. After manual review of all of the global nucleotide and protein alignments, a set of 1227 non-redundant feline sequences were selected as high confidence, high quality feline sequences. Within the set of 1227 sequences, 913 known sequences and 314 novel sequences were identified for which 914 were successfully mapped to their corresponding dog, human and mouse orthologs. Although additional non-redundant feline cDNA sequences we identified mapped to three or fewer orthologs across the four species, we limited our subsequent analysis to only those sequences for which all three non-feline species orthologs were confidently identified. This decision was made to ensure that our functional and comparative analysis would include only feline cDNA sequences for which dog, mouse and human orthologs were identified. Of the 914 orthologous sequence set, 844 sequences corresponded to known feline sequences and 70 corresponded to novel sequences (see Figure 1). Additional file 1, Table S1 contains the complete set of 1227 nonredundant nucleotide and protein sequences. The complete set of 914 orthologous sequences is listed in Additional file 2, Table S2 along with the designation of known or novel and the corresponding ensembl gene, transcript and protein identifiers for the dog, human and mouse orthologs.

It is interesting to note that compared to the existing public feline sequences, the sequences we identified exhibited a trend toward longer length and fewer sequencing errors. For example, of the 913 sequences that correspond to known feline public sequences, 309 of the public sequences contain a non-nucleotide sequence character such as an $\mathrm{N}$ or an $\mathrm{X}$. Within those public sequences containing N's or X's, 292 are shorter than the corresponding sequence we identified and only 17 of the public sequences containing non nucleotide letters are longer than the sequences we identified. Within the set of 604 public sequences mapped to our known sequences that do not contain N's or X's, 597 public feline sequences are shorter in length than the feline sequence we identified with only 7 public sequences having a longer length than our feline sequences. Figure 2 shows the distribution of nucleotide and protein sequence lengths for our set of 1227 sequences.

\section{Comparative Gene Expression Analysis}

The sequences we report were obtained from extensive sequencing of 21 individual tissue cDNA libraries and 1 pooled cDNA library. It is well known that while some 


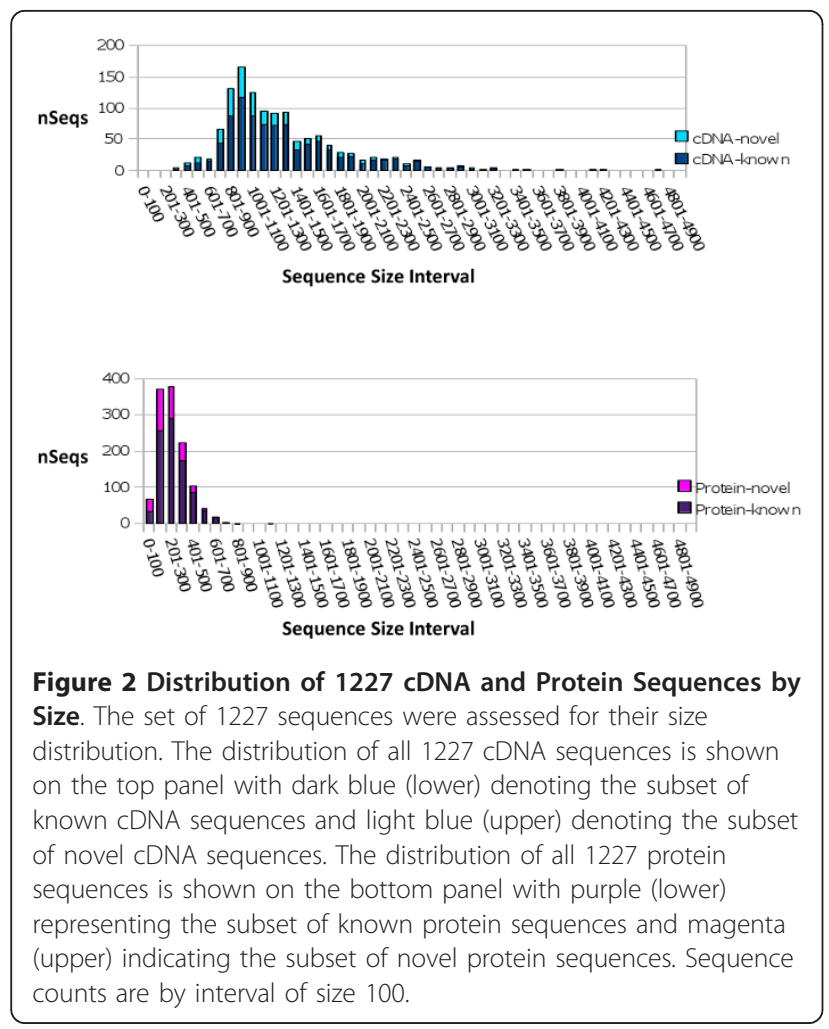

genes may exhibit rather narrow ranges of expression across tissues and cell types, many genes exhibit expression across numerous tissues and cell types [37,38]. We chose to leverage the orthologous relationships among our sequences to infer gene expression patterns across a set of anatomical regions.

When considering the inferred gene expression patterns as a function of anatomical regions, we were able to identify 114 anatomical regions exhibiting expression of 766 genes encoding our sequences. The range of gene counts, we identified, was from 1 gene each in lymph, rectum and cerebrum to 752 genes for the anatomical term lung. The eight anatomical terms exhibiting the lowest gene counts with more than a single gene include middle ear, corpus callosum and trachea $(2$ genes each, $0.21 \%$ ), subthalamic nucleus and foreskin (3 genes each, $0.32 \%$ ), epidermis and ciliary body (4 genes each, $0.44 \%)$ followed by adrenal medulla and internal ear (5 genes each, $0.54 \%)$. The eight anatomical terms exhibiting the greatest gene counts, each contain at least $73 \%$ of the genes corresponding to our cDNA sequences. The top eight anatomical regions listed in ascending order are liver (668 genes, $73 \%)$, skin (676 genes, $74 \%$ ), colon (686 genes, $75 \%$ ), placenta (689 genes, $75 \%$ ), kidney (693 genes, 76\%), testis (703 genes, $77 \%)$, brain (725 genes, $79 \%$ ) and lung (752 genes, $82 \%$ ). Table 1 contains the anatomical gene expression annotation results.
Table 1 Inferred Anatomical Gene Expression Patterns

\begin{tabular}{|c|c|c|}
\hline Anatomical Region & Number of Genes & $\%$ of Genes \\
\hline adrenal cortex & 206 & 22.5383 \\
\hline adrenal gland & 195 & 21.3348 \\
\hline adrenal medulla & 5 & 0.547 \\
\hline alveolus & 164 & 17.9431 \\
\hline amnion & 27 & 2.954 \\
\hline amniotic fluid & 61 & 6.674 \\
\hline amygdala & 39 & 4.267 \\
\hline aorta & 234 & 25.6018 \\
\hline artery & 53 & 5.7987 \\
\hline atrium & 13 & 1.4223 \\
\hline bile duct & 247 & 27.0241 \\
\hline bladder & 365 & 39.9344 \\
\hline blood & 546 & 59.7374 \\
\hline bone & 598 & 65.4267 \\
\hline bone marrow & 399 & 43.6543 \\
\hline brain & 725 & 79.3217 \\
\hline breast & 474 & 51.86 \\
\hline cartilage & 494 & 54.0481 \\
\hline cerebellum & 121 & 13.2385 \\
\hline cerebellum cortex & 43 & 4.7046 \\
\hline cerebral cortex & 85 & 9.2998 \\
\hline cerebrum & 1 & 0.1094 \\
\hline cervix & 443 & 48.4683 \\
\hline choroid & 469 & 51.3129 \\
\hline ciliary body & 4 & 0.4376 \\
\hline cochlea & 158 & 17.2867 \\
\hline colon & 686 & 75.0547 \\
\hline cornea & 149 & 16.302 \\
\hline corpus callosum & 2 & 0.2188 \\
\hline developmental & 34 & 3.7199 \\
\hline duodenum & 138 & 15.0985 \\
\hline dura mater & 58 & 6.3457 \\
\hline endometrium & 518 & 56.674 \\
\hline epidermis & 4 & 0.4376 \\
\hline epididymis & 92 & 10.0656 \\
\hline foreskin & 3 & 0.3282 \\
\hline fovea centralis & 434 & 47.4836 \\
\hline frontal lobe & 356 & 38.9497 \\
\hline gall bladder & 70 & 7.6586 \\
\hline ganglion & 9 & 0.9847 \\
\hline germinal center & 438 & 47.9212 \\
\hline greater omentum & 16 & 1.7505 \\
\hline gum & 21 & 2.2976 \\
\hline head and neck & 428 & 46.8271 \\
\hline heart & 629 & 68.8184 \\
\hline hippocampus & 301 & 32.9322 \\
\hline hypopharynx & 102 & 11.1597 \\
\hline
\end{tabular}


Table 1 Inferred Anatomical Gene Expression Patterns (Continued)

\begin{tabular}{|c|c|c|}
\hline hypothalamus & 311 & 34.0263 \\
\hline internal ear & 5 & 0.547 \\
\hline intestine & 313 & 34.2451 \\
\hline iris & 138 & 15.0985 \\
\hline islets of Langerhans & 557 & 60.9409 \\
\hline kidney & 693 & 75.8206 \\
\hline lacrimal gland & 69 & 7.5492 \\
\hline larynx & 239 & 26.1488 \\
\hline lens & 475 & 51.9694 \\
\hline liver & 668 & 73.0853 \\
\hline lung & 752 & 82.2757 \\
\hline lymph & 1 & 0.1094 \\
\hline lymph node & 426 & 46.6083 \\
\hline lymphoreticular & 164 & 17.9431 \\
\hline macula lutea & 434 & 47.4836 \\
\hline mammary gland & 544 & 59.5186 \\
\hline medulla oblongata & 144 & 15.7549 \\
\hline meninges & 57 & 6.2363 \\
\hline mesenchyma & 36 & 3.9387 \\
\hline middle ear & 2 & 0.2188 \\
\hline muscle & 242 & 26.477 \\
\hline myocardium & 130 & 14.2232 \\
\hline nasopharynx & 240 & 26.2582 \\
\hline nervous & 9 & 0.9847 \\
\hline oesophagus & 85 & 9.2998 \\
\hline optic nerve & 445 & 48.6871 \\
\hline oral cavity & 21 & 2.2976 \\
\hline ovary & 660 & 72.2101 \\
\hline pancreas & 568 & 62.1444 \\
\hline parathyroid & 490 & 53.6105 \\
\hline peripheral nerve & 104 & 11.3786 \\
\hline pharynx & 336 & 36.7615 \\
\hline pia mater & 57 & 6.2363 \\
\hline pineal body & 65 & 7.1116 \\
\hline pineal gland & 120 & 13.1291 \\
\hline pituitary gland & 218 & 23.8512 \\
\hline placenta & 689 & 75.3829 \\
\hline prostate & 651 & 71.2254 \\
\hline rectum & 1 & 0.1094 \\
\hline retina & 568 & 62.1444 \\
\hline salivary gland & 386 & 42.2319 \\
\hline skeletal muscle & 503 & 55.0328 \\
\hline skin & 676 & 73.9606 \\
\hline small intestine & 28 & 3.0635 \\
\hline smooth muscle & 134 & 14.6608 \\
\hline spinal cord & 36 & 3.9387 \\
\hline spinal ganglion & 122 & 13.3479 \\
\hline
\end{tabular}

Table 1 Inferred Anatomical Gene Expression Patterns (Continued)

\begin{tabular}{|c|c|c|}
\hline spleen & 571 & 62.4726 \\
\hline stomach & 641 & 70.1313 \\
\hline substantia nigra & 13 & 1.4223 \\
\hline subthalamic nucleus & 3 & 0.3282 \\
\hline sympathetic chain & 121 & 13.2385 \\
\hline synovium & 69 & 7.5492 \\
\hline testis & 703 & 76.9147 \\
\hline thymus & 168 & 18.3807 \\
\hline thyroid & 430 & 47.046 \\
\hline tongue & 164 & 17.9431 \\
\hline tonsil & 144 & 15.7549 \\
\hline trabecular meshwork & 100 & 10.9409 \\
\hline trachea & 2 & 0.2188 \\
\hline trophoblast & 70 & 7.6586 \\
\hline umbilical cord & 53 & 5.7987 \\
\hline urinary & 108 & 11.8162 \\
\hline uterus & 661 & 72.3195 \\
\hline vein & 135 & 14.7702 \\
\hline visual apparatus & 583 & 63.7856 \\
\hline whole body & 480 & 52.5164 \\
\hline
\end{tabular}

The anatomical expression pattern of the gene corresponding to each cDNA sequence was inferred. The human orthologs of each CDNA sequence were used to infer anatomical gene expression patterns using expression data (egenetic data) obtained from biomart. The results include 114 anatomical regions exhibiting expression of 766 genes encoding the cDNA sequences. The number of genes with inferred expression in each region is indicated (Number of Genes), as well the percentage of genes with inferred expression in each region (\% of Genes).

The expression pattern annotation corresponding to cell type resulted in gene counts for 44 cell types ranging from 1 gene $(0.1 \%)$ each for brown adipose cell, platelet and eosinophil to 2 genes $(0.22 \%)$ in mast cell and 3 genes $(0.33 \%)$ in hepatocyte. A count of 13 genes (1.4\%) was obtained for monocytes, while counts of 33 genes $(3.7 \%)$ each were reported for both cardiac muscle cell and chondrocyte. At the other end of the expression spectrum, the term stem cell was associated with 626 genes $(70.8 \%)$, B-lymphocyte (628 genes, $70.7 \%)$, epithelium (604 genes, 68.5\%), retinal pigment epithelium (514 genes, 57\%), skeletal muscle cell (499 genes, 56.6\%), fibroblast (485 genes, 55\%) and germ cell (435 genes, $49 \%)$. The cell expression counts provide cellular expression annotation for 749 of our orthologous genes. Table 2 contains the counts for all of the cell type expression annotations.

The mapping of pathology term expression annotation with our orthologous gene sets resulted in 57 terms having gene counts. The terms with the fewest gene counts included ulcerative colitis, neoplasia, rheumatoid arthritis, cirrhosis, and hyperplasia each of which exhibited a 
Table 2 Inferred Cell Type Gene Expression Patterns

\begin{tabular}{|c|c|c|}
\hline Cell Type & Number of Genes & $\%$ of Genes \\
\hline adipocyte & 188 & 21.23 \\
\hline alveolar macrophage & 127 & 14.11 \\
\hline B-lymphoblast & 106 & 12.58 \\
\hline B-lymphocyte & 628 & 70.79 \\
\hline brown adipose & 1 & 0.11 \\
\hline cardiac muscle cell & 33 & 3.72 \\
\hline chondrocyte & 33 & 3.72 \\
\hline dendritic cell & 56 & 6.35 \\
\hline endothelium & 194 & 21.88 \\
\hline eosinophil & 1 & 0.11 \\
\hline epithelium & 604 & 68.49 \\
\hline fibroblast & 485 & 54.92 \\
\hline foam cell & 25 & 2.74 \\
\hline germ cell & 435 & 49.02 \\
\hline glial cell & 432 & 48.69 \\
\hline glioblast & 42 & 4.7 \\
\hline granulosa cell & 63 & 7.22 \\
\hline hepatocyte & 3 & 0.33 \\
\hline keratinocyte & 287 & 32.17 \\
\hline leukocyte & 295 & 33.26 \\
\hline lymphocyte & 86 & 9.63 \\
\hline macrophage & 194 & 21.88 \\
\hline mast cell & 2 & 0.22 \\
\hline melanocyte & 283 & 31.84 \\
\hline monocyte & 13 & 1.42 \\
\hline muscle cell & 233 & 26.37 \\
\hline myeloid cell & 149 & 17.4 \\
\hline natural killer cell & 339 & 38.84 \\
\hline neuroblast & 396 & 44.86 \\
\hline neuroepithelium & 143 & 16.19 \\
\hline neuron & 124 & 14 \\
\hline pericyte & 128 & 14.66 \\
\hline platelet & 1 & 0.11 \\
\hline proerythroblast & 65 & 7.77 \\
\hline promyeloblast & 14 & 1.86 \\
\hline promyelocyte & 44 & 5.03 \\
\hline retinal pigment epithelium & 514 & 57.55 \\
\hline skeletal muscle cell & 499 & 56.56 \\
\hline smooth muscle cell & 128 & 14.77 \\
\hline squamous cell & 376 & 42.67 \\
\hline stem cell & 626 & 70.79 \\
\hline T-lymphocyte & 359 & 40.92 \\
\hline transitional & 194 & 22.21 \\
\hline white adipose & 41 & 4.81 \\
\hline
\end{tabular}

The cell type expression pattern of the gene corresponding to each CDNA sequence was inferred. The human orthologs of each CDNA sequence were used to infer cell type gene expression patterns using expression data (egenetic data) obtained from biomart. The results include expression across 44 cell types. The number of genes with inferred expression in each cell type is indicated (Number of Genes), as well the percentage of genes with inferred expression in each cell type (\% of Genes).
Table 3 Inferred Pathology Gene Expression Patterns

\begin{tabular}{|c|c|c|}
\hline Pathology & Number of Genes & $\%$ of Genes \\
\hline ulcerative colitis & 1 & 0.1094 \\
\hline neoplasia & 1 & 0.1094 \\
\hline rheumatoid arthritis & 1 & 0.1094 \\
\hline cirrhosis & 1 & 0.1094 \\
\hline hyperplasia & 1 & 0.1094 \\
\hline choriocarcinoma & 6 & 0.6565 \\
\hline seminoma & 7 & 0.7659 \\
\hline carcinoma in situ & 10 & 1.0941 \\
\hline liposarcoma & 12 & 1.3129 \\
\hline Schwannoma & 13 & 1.5317 \\
\hline arthritis & 15 & 1.86 \\
\hline goitre & 21 & 2.6258 \\
\hline papillary serous carcinoma & 27 & 2.954 \\
\hline phaeochromocytoma & 29 & 3.3917 \\
\hline monocytic & 32 & 3.5011 \\
\hline schizophrenia & 59 & 6.7834 \\
\hline sarcoma & 62 & 6.8928 \\
\hline Denys-drash & 70 & 8.2057 \\
\hline Wilms & 76 & 8.4245 \\
\hline fibrosarcoma & 95 & 10.7221 \\
\hline Ewing's & 101 & 11.5974 \\
\hline osteosarcoma & 110 & 12.4726 \\
\hline lymphoblastic & 106 & 12.5821 \\
\hline hypertrophic cardiomyopathy & 126 & 14.2232 \\
\hline medulloblastoma & 141 & 15.6455 \\
\hline osteoarthritis & 145 & 16.0832 \\
\hline fibrothecoma & 150 & 17.3961 \\
\hline Burkitt's & 161 & 18.8184 \\
\hline lymphocytic & 180 & 20.2407 \\
\hline myeloma & 195 & 22.3195 \\
\hline glioma & 226 & 25.4923 \\
\hline enchondroma & 234 & 26.2582 \\
\hline rhabdomyosarcoma & 233 & 26.477 \\
\hline leukaemia & 234 & 26.9147 \\
\hline teratocarcinoma & 247 & 28.1182 \\
\hline myeloid & 247 & 28.2276 \\
\hline malignant tumour & 280 & 31.291 \\
\hline astrocytoma & 281 & 31.6193 \\
\hline insulinoma & 281 & 31.9475 \\
\hline retinoblastoma & 297 & 34.0263 \\
\hline cystic fibrosis & 302 & 34.1357 \\
\hline lymphoma & 309 & 35.3392 \\
\hline T-cell leukemia & 317 & 36.3239 \\
\hline adenoma & 345 & 38.2932 \\
\hline meningioma & 345 & 38.9497 \\
\hline leiomyosarcoma & 383 & 43.5449 \\
\hline carcinoid & 431 & 48.3589 \\
\hline ascites & 428 & 48.5777 \\
\hline
\end{tabular}


Table 3 Inferred Pathology Gene Expression Patterns (Continued)

\begin{tabular}{ccc}
\hline neuroblastoma & 451 & 51.0941 \\
\hline oligodendroglioma & 463 & 52.1882 \\
\hline melanoma & 475 & 54.0481 \\
\hline glioblastoma & 508 & 57.3304 \\
\hline chondrosarcoma & 580 & 65.4267 \\
\hline tumour & 633 & 71.663 \\
\hline adenocarcinoma & 684 & 77.5711 \\
\hline carcinoma & 715 & 80.9628 \\
\hline normal & 765 & 86.4333 \\
\hline
\end{tabular}

The pathology expression pattern of the gene corresponding to each CDNA sequence was inferred. The human orthologs of each cDNA sequence were used to infer pathology gene expression patterns using expression data (egenetic data) obtained from biomart. The results include 57 pathology terms exhibiting expression of the CDNA sequences. The number of genes with inferred expression in each type of pathology is indicated (Number of Genes), as well the percentage of genes with inferred expression in each type of pathology (\% of Genes).

count of 1 gene (0.1\%). These terms were immediately followed by choriocarcinoma ( 6 genes, $0.66 \%$ ), seminoma ( 7 genes, $0.77 \%)$, carcinoma in situ (10 genes, $1.1 \%$ ), liposarcoma (12 genes, $1.3 \%$ ) and schwannoma (13 genes, 1.5\%). The pathological terms with the greatest counts include normal (765 genes, 86.4\%), carcinoma (715 genes, $81 \%$ ), adenocarcinoma (684 genes, $77.5 \%$ ), tumor (633 genes, $72 \%$ ), chondrosarcoma (580 genes, $65 \%$ ) and glioblastoma (508 genes, 57\%). A total of 766 genes were annotated with pathological terms for gene expression. Table 3 indicates the annotated gene count corresponding to inferred gene expression for each of the pathological terms.

Finally, the gene expression annotation associated with developmental stages offers some insight into the overall timing of gene expression across an organism's life time. The results suggest that the greatest numbers of genes are associated with the developmental stage terms of fetus (724 genes, $82 \%$ ) and embryo (635 genes, $72 \%$ ) while the fewest genes are associated with developmental stage terms child (76 genes, 8.4\%) and adolescent (61 genes, 6.7\%). Additional developmental stage terms include specific weeks of gestation, such as week 4 (30 genes, 3.2\%), week 6 (50 genes, 5.6\%), week 8 (318 genes, $36.4 \%)$ as well as stages towards the end of gestation, such as week 26 (193 genes, 22\%), week 32 (97 genes, $11 \%$ ) and week 42 (314 genes, 35\%). Other developmental terms include stages indicated by years, such as 2 years (316 genes, 36\%), 3 years (173 genes, 20\%), 14 years (181 genes, $20 \%), 21$ years (53 genes, 6\%), 45 years (150 genes, $17 \%)$ and 89 years (133 genes, 15\%). The results are shown in Table 4.

Taken together these results suggest that the genes encoding the cDNA sequences we have identified
Table 4 Inferred Developmental Gene Expression Patterns

\begin{tabular}{|c|c|c|}
\hline Developmental Stage & Number of Genes & $\%$ of Genes \\
\hline embryo & 635 & 71.9912 \\
\hline fetus & 724 & 81.8381 \\
\hline infant & 211 & 23.8512 \\
\hline child & 76 & 8.4245 \\
\hline adolescent & 61 & 6.7834 \\
\hline adult & 753 & 85.1204 \\
\hline 4 weeks & 30 & 3.2823 \\
\hline 6 weeks & 50 & 5.5799 \\
\hline 7 weeks & 3 & 0.3282 \\
\hline 8 weeks & 318 & 36.4333 \\
\hline 9 weeks & 562 & 63.7856 \\
\hline 10 weeks & 253 & 29.3217 \\
\hline 11 weeks & 32 & 3.8293 \\
\hline 12 weeks & 367 & 41.5755 \\
\hline 14 weeks & 26 & 2.8446 \\
\hline 15 weeks & 55 & 6.4551 \\
\hline 16 weeks & 326 & 35.9956 \\
\hline 17 weeks & 179 & 19.6937 \\
\hline 18 weeks & 225 & 25.0547 \\
\hline 19 weeks & 594 & 67.1772 \\
\hline 20 weeks & 602 & 67.8337 \\
\hline 21 weeks & 307 & 33.9168 \\
\hline 22 weeks & 316 & 35.0109 \\
\hline 24 weeks & 324 & 36.5427 \\
\hline 26 weeks & 193 & 21.663 \\
\hline 32 weeks & 97 & 10.9409 \\
\hline 42 weeks & 314 & 35.3392 \\
\hline 2 years & 316 & 36.3239 \\
\hline 3 years & 173 & 19.8031 \\
\hline 6 years & 103 & 11.9256 \\
\hline 14 years & 181 & 20.4595 \\
\hline 16 years & 119 & 13.3479 \\
\hline 17 years & 35 & 3.9387 \\
\hline 19 years & 62 & 7.1116 \\
\hline 20 years & 49 & 5.5799 \\
\hline 21 years & 53 & 6.1269 \\
\hline 23 years & 193 & 21.7724 \\
\hline 24 years & 181 & 20.4595 \\
\hline 25 years & 308 & 34.7921 \\
\hline 26 years & 331 & 37.3085 \\
\hline 27 years & 277 & 31.1816 \\
\hline 28 years & 129 & 14.442 \\
\hline 31 years & 255 & 28.337 \\
\hline 34 years & 65 & 7.4398 \\
\hline 35 years & 22 & 2.6258 \\
\hline
\end{tabular}


Table 4 Inferred Developmental Gene Expression Patterns (Continued)

\begin{tabular}{|c|c|c|}
\hline 36 years & 150 & 17.1772 \\
\hline 40 years & 1 & 0.1094 \\
\hline 44 years & 27 & 2.954 \\
\hline 45 years & 150 & 17.0678 \\
\hline 46 years & 352 & 40.0438 \\
\hline 47 years & 2 & 0.2188 \\
\hline 48 years & 1 & 0.1094 \\
\hline 49 years & 252 & 28.4464 \\
\hline 55 years & 221 & 24.9453 \\
\hline 58 years & 1 & 0.1094 \\
\hline 60 years & 1 & 0.1094 \\
\hline 62 years & 226 & 25.3829 \\
\hline 64 years & 152 & 17.2867 \\
\hline 69 years & 182 & 20.5689 \\
\hline 70 years & 283 & 31.7287 \\
\hline 71 years & 230 & 25.8206 \\
\hline 72 years & 131 & 14.9891 \\
\hline 73 years & 1 & 0.1094 \\
\hline 74 years & 12 & 1.3129 \\
\hline 76 years & 10 & 1.0941 \\
\hline 79 years & 1 & 0.1094 \\
\hline 80 years & 133 & 14.8796 \\
\hline 89 years & 14 & 1.6411 \\
\hline
\end{tabular}

The developmental expression pattern of the gene corresponding to each cDNA sequence was inferred. The human orthologs of each CDNA sequence were used to infer developmental stage by week of gestation, year of age and life stage of human development. The number and percentage of genes with inferred expression in each stage is indicated in the second and third columns respectively.

exhibit considerably larger breadth of expression than would be suggested from the initial tissues that were sequenced. The broad extent of tissue, cell type, developmental and pathological expression annotation suggests that these sequences may include sequences underlying tissue and organ development as well as contributing to specific pathological conditions. In order to better understand the biological role of these genes we chose to combine the expression annotation with other functional and comparative annotation types.

\section{Gene Ontology Annotation Analysis}

Gene ontology (GO) annotation was performed on the feline sequences using the previously identified comparative genomics ortholog relationships. Gene ontology terms were mapped from human annotation files to feline orthologs. The initial gene ontology human molecular function annotation file contained 73,467 function annotation terms mapped to 21,956 human gene identifiers, corresponding to 3,085 unique gene ontology function terms. The cellular location gene ontology annotation file contained 975 unique terms mapped to 21,956 human genes resulting in 69,556 gene-term relationships. The biological process gene ontology annotation also contained 21,956 human gene identifiers consisting of 6518 unique gene ontology process annotation terms represented by 89,968 gene-to-GO entries.

The mapping of gene ontology functional annotation terms onto the non-redundant full length sequences resulted in 901 of our feline cDNA sequences becoming associated with 647 unique gene ontology molecular function annotation terms resulting in 3219 annotationgene relationships. Repeating the procedure to map the cellular location annotation, we mapped 3423 geneannotation relationships corresponding to 337 unique location annotation terms covering the set of 901 genes. Mapping the biological process annotation terms produced 4247 gene-to-GO annotations of which 1441 unique gene ontology process annotations mapped successfully to 901 genes.

Typically gene ontology annotation terms are filtered using an enrichment criterion that is calculated from a hypergeometric null model to describe the number of annotation terms one might expect to occur within a gene set of a given size and a GO annotation distribution of particular parameters. Although such an approach is necessary when attempting to determine the biological role of a gene set, such as up-regulated or down-regulated genes in a gene expression study, we did not calculate an enrichment of gene ontology terms, instead we combined the gene ontology annotation with measures of evolutionary selection using non-synonymous $(\mathrm{dN})$ versus synonymous $(\mathrm{dS})$ codon statistics as a means of exploring the evolutionary relationships that exist among the different gene ontology annotations across our cDNA sequences. A well accepted approach for identifying evidence of positive selection is to identify genes exhibiting significantly larger rates of nonsynonymous substitutions per non-synonymous site than synonymous substitutions per synonymous site. Evidence of fixation exists when the ratio of non-synonymous substitution rate to synonymous substitution rate equals zero $(\mathrm{dN} / \mathrm{dS}=0)$.

Evidence of negative selection exists when $\mathrm{dN} / \mathrm{dS}<1$ and evidence of positive selection exists when $\mathrm{dN} / \mathrm{dS}>$ 1. We recognize that using the $\mathrm{dN} / \mathrm{dS}$ value across an entire gene is an extremely conservative measure of selection, and that smaller regions within a gene may exhibit local signals of positive selection [39]. However, we chose the conservative approach in order to minimize reporting false positives due to the possibility of sequencing errors.

Instead of considering all of the genes we identified as a single gene set, we chose to select gene subsets using 
SQL queries in MySQL to identify cDNA sequences sharing gene ontology annotation terms for which we calculated an average $\mathrm{dN} / \mathrm{dS}$ value. From this analysis, we were able to identify annotation types exhibiting low $\mathrm{dN} / \mathrm{dS}$ values, corresponding to greater levels of sequence conservation across species. We were also able to identify annotation terms that exhibited considerably higher $\mathrm{dN} / \mathrm{dS}$ values indicating less negative selection in the act on some types of genes. Because we chose to employ a stringent criteria for positive selection, we did not identify genes exhibiting strong signals of positive selection, instead, we were able to identify genes and annotation types with different levels of selection pressure acting on them. Beginning with the gene ontology location annotation, an SQL query was performed such that the genes exhibiting the same location annotation terms were grouped together and the average $\mathrm{dN} / \mathrm{dS}$ value was calculated for cat versus dog, cat versus human and cat versus mouse. Location annotations occurring within gene sets that exhibit extremely low $\mathrm{dN} / \mathrm{dS}$ values and very low standard deviation of the $\mathrm{dN} / \mathrm{dS}$ value for each species were selected as negatively selected location annotation gene sets.

A number of genes grouped by the same gene ontology location annotation terms exhibited $\mathrm{dN} / \mathrm{dS}$ values close to zero, $(\mathrm{dN} / \mathrm{dS}<0.07)$. These genes were associated with several cellular themes which were each associated with multiple location annotation terms. See Figure 3 for a representative map of gene ontology location annotation terms across the $\mathrm{dN} / \mathrm{dS}$ values. The

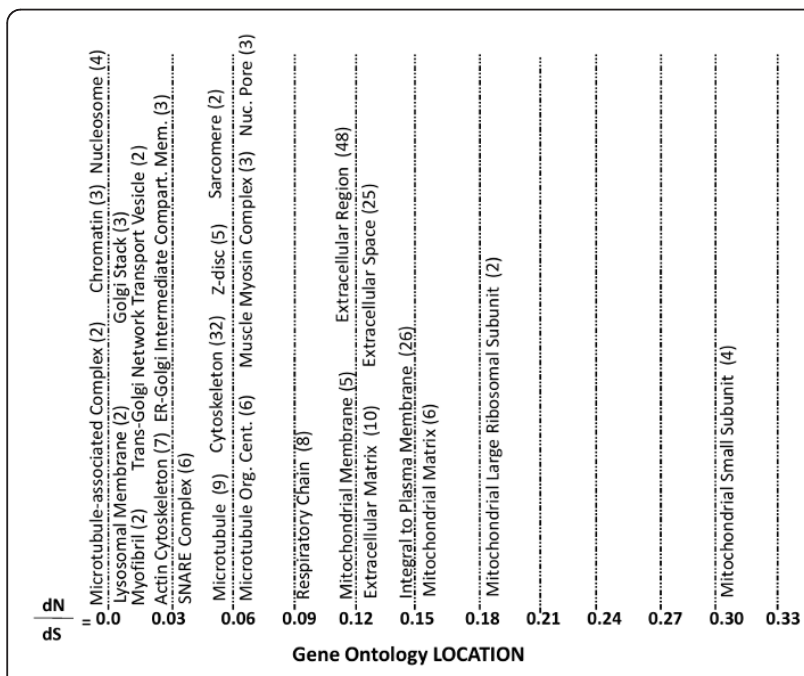

Figure 3 Gene Ontology Location Terms by dN/dS Value. Representative gene ontology location terms associated with the proteins encoded by the feline cDNA sequences were stratified by $\mathrm{dN} / \mathrm{dS}$ values of cat versus dog, human and mouse. The number of feline cDNAs associated with each annotation term is indicated in parentheses. following terms related to microtubules and cytoskeletal organization occurred: microtubule associated complex ( 2 genes, $\mathrm{dN} / \mathrm{dS}=0$ ), actin cytoskeleton (7 genes, $\mathrm{dN} / \mathrm{dS}$ $=0.03)$, microtubule ( 9 genes, $\mathrm{dN} / \mathrm{dS}=0.05)$, cytoskeleton (32 genes, $\mathrm{dN} / \mathrm{dS}=0.05$ ) and microtubule organizing center $(6$ genes, $\mathrm{dN} / \mathrm{dS}=0.06)$. A muscle theme was present within the negatively selected location annotations. Muscle associated location terms included myofibril ( 2 genes, $\mathrm{dN} / \mathrm{dS}=0.02), \mathrm{Z}$ disc ( 5 genes, $\mathrm{dN} / \mathrm{dS}=$ 0.04 ), sarcomere ( 2 genes, $\mathrm{dN} / \mathrm{dS}=0.05$ ) and muscle myosin complex (3 genes, $\mathrm{dN} / \mathrm{dS}=0.06)$. Additional location terms within this group included chromatin (3 genes, $\mathrm{dN} / \mathrm{dS}=0$ ), nucleosome (4 genes, $\mathrm{dN} / \mathrm{dS}=0$ ) and nuclear pore ( 3 genes, $\mathrm{dN} / \mathrm{dS}=0.06)$. The last theme observed within this group relates to intracellular trafficking and includes terms such as lysosomal membrane ( 2 genes, $\mathrm{dN} / \mathrm{dS}=0.01$ ), golgi stack ( 3 genes, $\mathrm{dN} /$ $\mathrm{d} S=0.01)$, trans golgi network transport vesicle (2 genes, $\mathrm{dN} / \mathrm{dS}=0.02)$, ER-Golgi intermediate compartment membrane ( 3 genes, $\mathrm{dN} / \mathrm{dS}=0.03$ ) and SNARE complex (6 genes, $\mathrm{dN} / \mathrm{dS}=0.04)$.

Location annotation terms associated with genes exhibiting a larger $\mathrm{dN} / \mathrm{dS}$ value included extracellular region (48 genes, $\mathrm{dN} / \mathrm{dS}=0.12$ ), extracellular matrix (10 genes, $\mathrm{dN} / \mathrm{dS}=0.13)$, extracellular space (25 genes, $\mathrm{dN} / \mathrm{dS}=$ 0.13 ) and integral to plasma membrane (26 genes, $\mathrm{dN} /$ $\mathrm{dS}=0.14)$. Some of the location terms with the greatest $\mathrm{dN} / \mathrm{dS}$ values were associated with the mitochondria, for example respiratory chain $(8$ genes, $\mathrm{dN} / \mathrm{dS}=0.1)$, mitochondrial membrane ( 5 genes, $\mathrm{dN} / \mathrm{dS}=0.12$ ), mitochondrial matrix (6 genes, $\mathrm{dN} / \mathrm{dS}=0.16)$, mitochondrial large ribosomal subunit ( 2 genes, $\mathrm{dN} / \mathrm{dS}=0.19$ ) and mitochondrial small subunit ( 4 genes, $\mathrm{dN} / \mathrm{dS}=0.31$ ).

Similar themes were observed within the gene ontology process annotation data. See Figure 4 for a representative map of gene ontology process annotation by $\mathrm{dN} / \mathrm{dS}$ values. The microtubule theme was represented by the terms microtubule-based process ( 3 genes, $\mathrm{dN} / \mathrm{dS}$ $=0$ ), microtubule-based movement ( 2 genes, $\mathrm{dN} / \mathrm{dS}=$ $0)$, cytoskeleton organization ( 2 genes, $\mathrm{dN} / \mathrm{dS}=0$ ), microtubule cytoskeleton organization ( 2 genes, $\mathrm{dN} / \mathrm{dS}$ $=0$ ), positive regulation of actin filament polymerization ( 2 genes, $\mathrm{dN} / \mathrm{dS}=0.01$ ), cytokinesis $(4$ genes, $\mathrm{dN} / \mathrm{dS}=$ $0.02)$, centriole replication ( 2 genes, $\mathrm{dN} / \mathrm{dS}=0.02)$, regulation of cytokinesis ( 2 genes, $\mathrm{dN} / \mathrm{dS}=0.02$ ) and actin cytoskeleton organization (9 genes, $\mathrm{dN} / \mathrm{dS}=0.04$ ). Much like the location annotation, a theme observed in the process annotation related to intracellular transport and included terms such as protein retention in ER lumen ( 2 genes, $\mathrm{dN} / \mathrm{dS}=0)$, calcium ion transport ( 3 genes, $\mathrm{dN} / \mathrm{dS}=0.01)$, golgi to endosome transport $(2$ genes, $\mathrm{dN} / \mathrm{dS}=0.01$ ), vesicle docking involved in exocytosis (2 genes, $\mathrm{dN} / \mathrm{dS}=0.02$ ) and retrograde transport, endosome to Golgi (3 genes, $\mathrm{dN} / \mathrm{dS}=0.03$ ). Also 


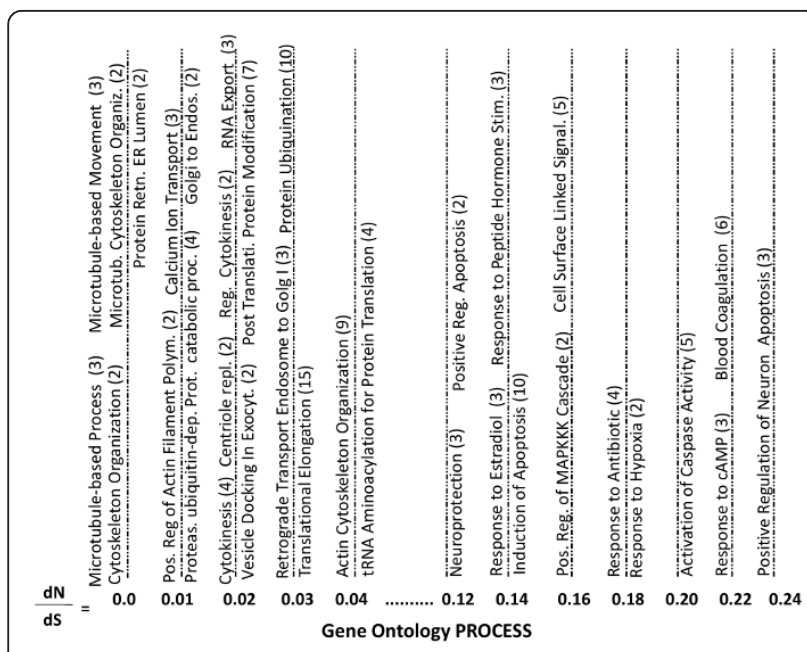

Figure 4 Gene Ontology Process Terms by dN/dS Value. A representative sample of gene ontology process terms associated with the proteins encoded by the feline cDNA sequences were stratified by dN/dS values of cat versus dog, human and mouse. The number of feline cDNAs associated with each annotation term is indicated in parentheses.

present, was a protein synthesis/degradation theme supported by the terms proteasomal ubiquitin-dependent protein catabolic process ( 4 genes, $\mathrm{dN} / \mathrm{dS}=0.01$ ), posttranslational protein modification (7 genes, $\mathrm{dN} / \mathrm{dS}=$ 0.02 ), RNA export from nucleus (3 genes, $\mathrm{dN} / \mathrm{dS}=$ $0.02)$, protein ubiquination (10 genes, $\mathrm{dN} / \mathrm{dS}=0.03$ ), translational elongation ( 15 genes, $\mathrm{dN} / \mathrm{dS}=0.03$ ) and tRNA aminoacylation for protein translation (4 genes, $\mathrm{dN} / \mathrm{dS}=0.04$ ). In contrast, process annotation terms exhibiting relatively large $\mathrm{dN} / \mathrm{dS}$ ratios overlapped with themes of cellular signalling and regulation/response of cells to environmental signals.

Examples of process terms relating to these themes include neuroprotection ( 3 genes, $\mathrm{dN} / \mathrm{dS}=0.13$ ), positive regulation of apoptosis ( 2 genes, $\mathrm{dN} / \mathrm{dS}=0.13$ ), response to estradiol stimulus (6 genes, $\mathrm{dN} / \mathrm{dS}=0.14$ ), response to peptide hormone stimulus (3 genes, $\mathrm{dN} / \mathrm{dS}$ $=0.14)$, induction of apoptosis (10 genes, $\mathrm{dN} / \mathrm{dS}=0.15)$, positive regulation of MAPKKK cascade ( 2 genes, $\mathrm{dN} / \mathrm{dS}$ $=0.16)$, cell surface receptor linked signalling pathway ( 5 genes, $\mathrm{dN} / \mathrm{dS}=0.16$ ), response to antibiotic (4 genes, $\mathrm{dN} / \mathrm{dS}=0.18$ ), response to hyperoxia (2 genes, $\mathrm{dN} / \mathrm{dS}=$ 0.19 ), activation of caspase activity ( 5 genes, $\mathrm{dN} / \mathrm{dS}=$ 0.21 ), response to cAMP ( 3 genes, $\mathrm{dN} / \mathrm{dS}=0.22$ ), positive regulation of neuron apoptosis ( 3 genes, $\mathrm{dN} / \mathrm{dS}=$ 0.24 ) and blood coagulation (6 genes, $\mathrm{dN} / \mathrm{dS}=0.22$ ).

The gene ontology annotation for molecular function provides information about the structural and functional role of gene products. The overall theme within the low $\mathrm{dN} / \mathrm{dS}$ group of function annotation involved molecules contributing to specific binding events (see Figure 5).

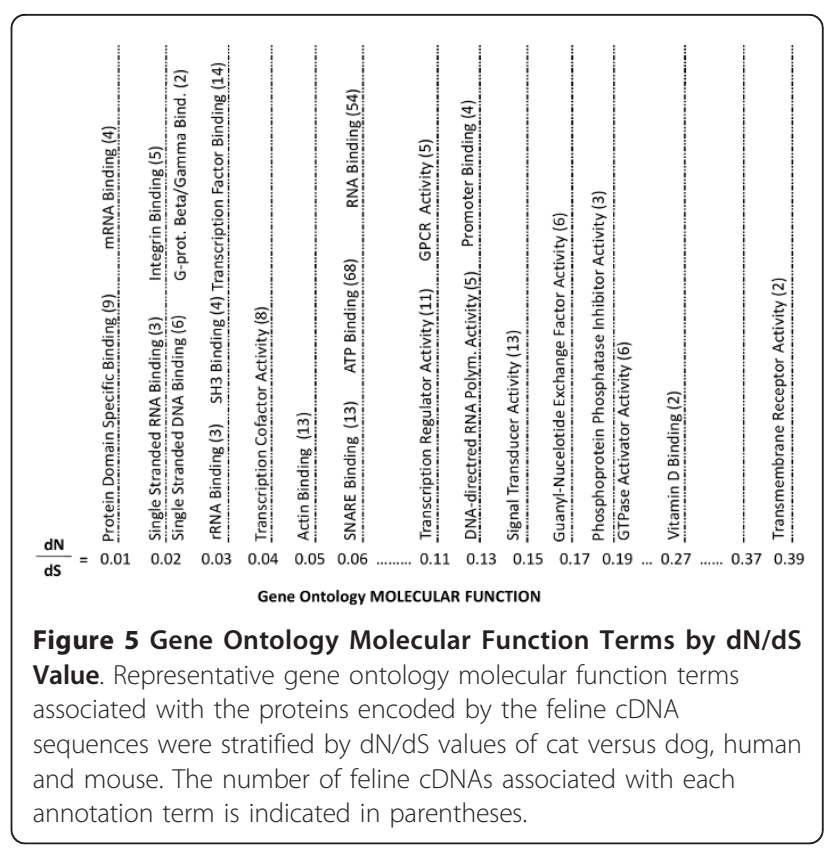

Some of the annotation that supported this theme includes protein domain specific binding ( 9 genes, $\mathrm{dN} /$ $\mathrm{dS}=0.01$ ), mRNA binding ( 4 genes, $\mathrm{dN} / \mathrm{dS}=0.01$ ), single stranded RNA binding ( 3 genes, $\mathrm{dN} / \mathrm{dS}=0.02$ ), integrin binding ( 5 genes, $\mathrm{dN} / \mathrm{dS}=0.02$ ), single stranded DNA binding (6 genes, $\mathrm{dN} / \mathrm{dS}=0.02)$, G-protein beta/ gamma-subunit binding ( 2 genes, $\mathrm{dN} / \mathrm{dS}=0.02$ ), rRNA binding ( 3 genes, $\mathrm{dN} / \mathrm{dS}=0.03$ ), $\mathrm{SH} 3$ binding (4 genes, $\mathrm{dN} / \mathrm{dS}=0.03$ ), transcription factor binding (14 genes, $\mathrm{dN} / \mathrm{dS}=0.03)$, transcription factor coactivator activity (8 genes, $\mathrm{dN} / \mathrm{dS}=0.04)$, actin binding $(13$ genes, $\mathrm{dN} / \mathrm{dS}$ $=0.05)$, SNARE binding ( 4 genes, $\mathrm{dN} / \mathrm{dS}=0.06$ ), ATP binding ( 68 genes, $\mathrm{dN} / \mathrm{dS}=0.06)$ and RNA binding (54 genes, $\mathrm{dN} / \mathrm{dS}=0.06$ ). The theme associated with higher $\mathrm{dN} / \mathrm{dS}$ associations with gene ontology molecular function annotation paralleled the theme observed in the high $\mathrm{dN} / \mathrm{dS}$ biological process annotation, cellular response and signal transduction.

Function annotation terms associated with higher dN/ $\mathrm{dS}$ values include transcription regulator activity (11 genes, $\mathrm{dN} / \mathrm{dS}=0.11$ ), G-protein coupled receptor activity ( 5 genes, $\mathrm{dN} / \mathrm{dS}=0.11$ ), DNA directed RNA polymerase activity ( 5 genes, $\mathrm{dN} / \mathrm{dS}=0.13$ ), signal transducer activity (13 genes, $\mathrm{dN} / \mathrm{dS}=0.14$ ), promoter binding ( 4 genes, $\mathrm{dN} / \mathrm{dS}=0.13)$, guanyl-nucleotide exchange factor activity (6 genes, $\mathrm{dN} / \mathrm{dS}=0.17$ ), phosphoprotein phosphatase inhibitor activity (3 genes, $\mathrm{dN} / \mathrm{dS}=0.18$ ), GTPase activator activity ( 6 genes, $\mathrm{dN} / \mathrm{dS}=0.19)$, vitamin $\mathrm{D}$ binding $(2$ genes, $\mathrm{dN} / \mathrm{dS}=0.26)$ and transmembrane receptor activity ( 2 genes, $\mathrm{dN} / \mathrm{dS}=0.39$ ).

The themes observed in this data provide insight into the inner workings of the cell and shed light on the 
evolutionary constraints that act on different components of the intracellular machinery. The fact that the these feline sequences include a distribution of gene products, some of which are strongly conserved across human/mouse/dog, suggests that these sequences include genes that play very important roles in critical cellular processes and correspond to conserved mammalian cellular biology. However, some genes map to protein products that have relatively less selective pressure acting on them. These gene products are also important because they represent the targets of adaptive evolution within the cell. While microtubule structure and function must be highly conserved, regulatory gene products are freer to evolve new interactions that may increase fitness of the cell. Figures 3 through 5 contain the three types of gene ontology annotation together with the average $d N / d S$ values for genes exhibiting the same annotation types. Although this analysis of $\mathrm{dN} / \mathrm{dS}$ values across our genes provided a gene level picture of our data, we wanted to investigate the large-scale pattern of $\mathrm{dN} / \mathrm{dS}$ values across our cDNA sequences.

\section{GeneGO Analysis of Orthologous Genes by dN/dS Value}

In order to gain a more global view of how the feline cDNA sequences compared to other species, a set of 711 cDNA sequences having orthologs containing gene ontology annotation across dog, mouse and human were analysed to detect any non-random patterns across the genes, species and annotations. We sorted a list of 711 genes by $\mathrm{dN} / \mathrm{dS}$ value and identified 3 groupings, corresponding to the top $25 \%$ of $\mathrm{dN} / \mathrm{dS}$ values, the bottom $25 \%$ of $\mathrm{dN} / \mathrm{dS}$ values and the middle $50 \%$ of $\mathrm{dN} / \mathrm{dS}$ values. Each list was used to query the GeneGO annotation database for metabolic pathways.

The GeneGO database is based on the data and annotation of the Gene Ontology (GO) consortium which has collated biological annotations regarding the known or inferred roles of gene products, providing a powerful resource for identifying relationships among groups of genes, and thereby allowing the expansion of data analysis from single genes to gene sets. The GeneGO sowftare package identifies enrichment gene sets corresponding to metabolic and/or signalling networks using a hypergeometric model to calculate the null model probability for a set of genes. Enrichment is identified as an extremely unlikely probability under the null model. The results obtained by the GeneGO analysis indicate that the genes exhibiting higher $\mathrm{dN} / \mathrm{dS}$ values were associated with specific metabolic pathways and biological processes. (Figure 6).

The heat map shows that for most genes, the $\mathrm{dN} / \mathrm{dS}$ values are similar across different species. In order to see if any selection bias exists for different metabolic pathway annotations, the 711 genes were divided into 3

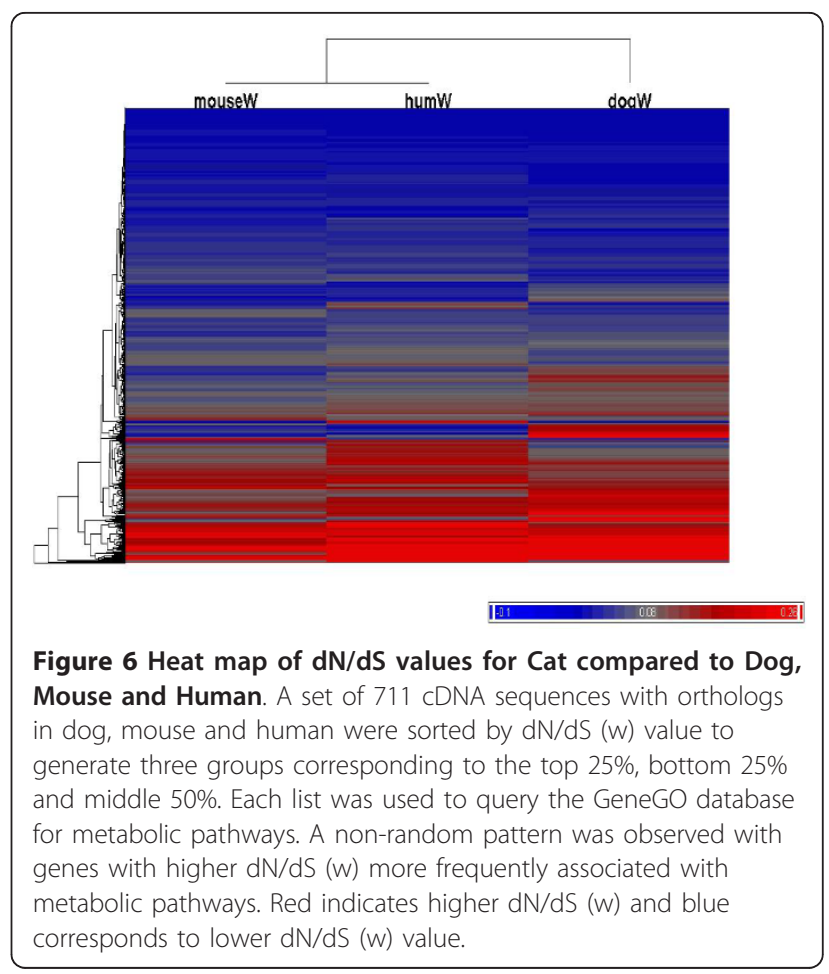

groups according to $\mathrm{dN} / \mathrm{dS}$ value from dog/cat group. The first group contains the most conserved 178 genes with $\mathrm{dN} / \mathrm{dS}$ values less than 0.0149 , the second group contains the most divergent 178 genes with $\mathrm{dN} / \mathrm{dS}$ values greater than 0.1229 . The third group contains the remainder of genes having $\mathrm{dN} / \mathrm{dS}$ values between 0.0149 and 0.1229 (see Table 5).

We examined the metabolic networks of these genes in GeneGO. We observed that the group with lower $\mathrm{dN} / \mathrm{dS}$ values exhibited fewer numbers of amino acid type metabolic networks than the group with larger $\mathrm{dN}$ / $\mathrm{dS}$ values. Our examination of these metabolic network annotations across the groups of genes provides insight into an interesting pattern that was not apparent from the gene level gene ontology analysis described in the preceding section.

We discovered that the group of genes with smaller $\mathrm{dN} / \mathrm{dS}$ values are in metabolic networks exhibiting enrichment for carbohydrate metabolism, while the group with larger $\mathrm{dN} / \mathrm{dS}$ values is associated with more metabolic networks involved in amino acid metabolism (See Table 6). Such patterns of more negative selection acting on carbohydrate metabolism and relatively less negative selection acting on amino acid metabolism may underlie an adaptive evolutionary role for genes associated with amino acid metabolism between obligate carnivores and omnivores. This result is in agreement with known differences in amino acid nutritional requirements between different species. This suggests 
Table 5 Summary Statistics for GeneGO Annotation Analysis

\begin{tabular}{|c|c|c|c|c|c|}
\hline & $\begin{array}{c}\text { All } \\
\text { genes; } \\
\text { All } d N / \\
d S\end{array}$ & $\begin{array}{c}\text { Top 25\%; } \\
d N / d S< \\
0.0149\end{array}$ & $\begin{array}{c}\text { Middle } 50 \% \\
0.0149<d N / d S< \\
0.1229\end{array}$ & $\begin{array}{c}\text { Bottom 25\%; } \\
d N / d S> \\
0.1229\end{array}$ & $\begin{array}{l}\text { Common networks between top } 25 \% \text { and bottom } \\
\qquad 25 \%\end{array}$ \\
\hline Genes & 711 & 178 & 355 & 178 & \\
\hline $\begin{array}{l}\text { Metabolic } \\
\text { Networks }\end{array}$ & 91 & 29 & 79 & 42 & 12 \\
\hline $\begin{array}{l}\text { Network/Gene } \\
\text { Ratio }\end{array}$ & $12.8 \%$ & $16.3 \%$ & $22.3 \%$ & $23.6 \%$ & \\
\hline
\end{tabular}

that depending on dietary sources and metabolic requirements, the evolution rate may not be the same across all metabolic networks. These results provide an initial analysis of these genes and might be interpreted to suggest that genes associated with amino acid metabolism and biochemical utilization might have undergone different evolutionary selection among obligate carnivores compared to omnivores and herbivores. Such a hypothesis requires further exploration and may ultimately provide the genomic rationale of the need for feline specific nutritional needs that are distinct from other species, including dog.

\section{Identification of Metabolic and Biochemical Pathways}

Based on the GeneGO findings, we wanted to gain further insight into the biochemical role of the feline cDNA sequences. We chose to further explore how our cDNA sequences map onto metabolic pathways by identifying a set of pathways for which at least one pathway member has been identified in the set of our orthologous cat cDNA sequences. This analysis identified ten distinct classes of biochemical pathways for which 112 feline cDNA sequences have been mapped to 75 different pathways.

The categories of pathways include amino acid metabolism, biosynthesis of secondary metabolites, carbohydrate metabolism, energy metabolism, lipid metabolism, nucleotide metabolism as well as glycan biosynthesis and metabolism, metabolism of cofactors and vitamins and xenobiotic biodegradation and metabolism.

We identified 29 cDNA sequences in pathways underlying common amino acid metabolism pathways and 9 cDNA sequences involved in other amino acid metabolic pathways. We found 29 cDNA sequences that are involved in the metabolism of carbohydrates, 19 cDNA sequences involved in energy metabolism, 7 cDNA sequences associated with glycan biosynthesis and metabolism and 33 cDNA sequences that are involved in lipid metabolism. Additionally, we have identified 18 sequences that participate in the metabolism of cofactors and vitamins, $16 \mathrm{cDNA}$ sequences that are involved in nucleotide metabolism and 12 that are involved in xenobiotic biodegradation and metabolism. Table 7 provides a summary of gene counts for these pathways.

Table 6 Conserved and Divergent Metabolic Pathways

\begin{tabular}{|c|c|c|c|}
\hline Most conserved & $\begin{array}{c}p- \\
\text { value }\end{array}$ & Most divergent & $\begin{array}{c}p- \\
\text { value }\end{array}$ \\
\hline 1-icosatrienoyl-sn-glycero-3-phosphocholine pathway & $\begin{array}{c}6.01 \mathrm{E}- \\
03\end{array}$ & (L)-leucine pathways and transport & $2.42 \mathrm{E}^{-03}$ \\
\hline $\begin{array}{c}\text { 1-docosahexaenoyl-glycerol_3-phosphocholine } \\
\text { pathway }\end{array}$ & $6.96 \mathrm{E}^{-03}$ & GalNAcbeta1-3Gal pathway & $3.06 \mathrm{E}^{-03}$ \\
\hline 2-arachidonoyl-glycerol_3-phosphocholine pathway & $8.16 \mathrm{E}^{-03}$ & Branched-chain amino acid metabolism & $4.08 \mathrm{E}^{-03}$ \\
\hline Phosphatidylinositol-3,4,5-triphosphate pathway & $1.61 \mathrm{E}^{-02}$ & Estrone and Estradiol metabolism & $2.23 \mathrm{E}^{-02}$ \\
\hline [O-hexadecanoyl-(L)-carnitine pathway & $2.10 \mathrm{E}^{-02}$ & N-acyl-sphingosine phosphate pathway & $2.48 \mathrm{E}^{-02}$ \\
\hline Phosphatidylinositol-4,5-diphosphate pathway & $3.18 \mathrm{E}^{-02}$ & HETE, HPETE and Leukotriene4 metabolism & $6.47 \mathrm{E}^{-02}$ \\
\hline Glutamic acid pathway & $3.83 \mathrm{E}^{-02}$ & Tryptophan, Phenylalanine, Methionine metabolism & $7.02 \mathrm{E}^{-02}$ \\
\hline L-glutamate pathways and transport & $5.94 \mathrm{E}^{-02}$ & $\begin{array}{c}\text { Tryptophan, Phenylalanine, Tyramine, Methionine metabolism and } \\
\text { transport }\end{array}$ & $8.30 \mathrm{E}^{-02}$ \\
\hline Glycolysis, Glucogenesis and glucose transport & $6.26 \mathrm{E}^{-02}$ & Lyso-Phosphatidylserine pathway & $8.88 \mathrm{E}^{-02}$ \\
\hline Glutamic acid pathways and transport & $6.83 \mathrm{E}^{-02}$ & Cholesterol biosynthesis & $1.13 \mathrm{E}^{-01}$ \\
\hline
\end{tabular}

The ten most highly conserved, and the ten most highly divergent metabolic pathways are listed along with the $p$-value for each pathway. The most conserved pathways are associated with the lowest $\mathrm{dN} / \mathrm{dS}$ values, whereas the most divergent pathways are associated with the highest $\mathrm{dN} / \mathrm{dS}$ values. 


\section{Comparative Phenotype Analysis}

Phenotype annotation can provide additional information regarding the physiological function of a gene. Although our dataset includes 1227 cDNA sequences, one of our goals was to identify a relatively small subset of feline genes that represent important clinical, developmental and nutritional aspects of feline biology. This comparative phenotype analysis resulted in the identification of a pleiotropic set of genes that were partitioned into seven phenotype modules, each of which contains a relatively small number of genes that contribute to a comparatively large set of feline relevant phenotypes. The term phenotype module was adapted from the notion of a gene expression module, in which the set of genes exhibit similar patterns of spatial or temporal expression. Each phenotype module was constructed by grouping genes exhibiting related phenotypes based upon the phenotype classes described in the mammalian phenotype browser [40]. Similar phenotypes were grouped by body system and/or common biological processes to create the final set of phenotype modules. These seven modules provide a body system distributed view of the phenotypic roles of some of the genes that encode our 1227 cDNA sequences. The modules, genes and associated phenotypes are included in Table 8.

The cardiac module consists of eight genes and is associated with the following eight phenotypes: cardiac hypertrophy, dilated dorsal aorta, abnormal mitral valve morphology, abnormal cardiac output, abnormal myocardial fiber physiology, enlarged heart, abnormal outflow tract and abnormal coronary artery morphology. This module contains genes that are of relevance to feline cardiac disease such as hypertrophic cardiomyopathy and developmental defects of the heart.

The developmental-patterning module consists of seven genes and is associated with phenotypes that include abnormal mesoderm development, abnormal proximal/distal developmental patterning and abnormal rostral/caudal developmental patterning. Within this module we identified genes associated with distinct cell differentiation and specification properties such as embryonic growth arrest, abnormal trophoblast layer morphology and abnormal white adipose tissue. Additional phenotypes within this module were associated with retinal formation, renal function, intestine morphology as well as cholesterol, triglyceride and corticosterone levels. The phenotypes within this module may be useful in dissecting the genetic mechanisms underlying inherited developmental abnormalities in both domestic and endangered felids.

The third module is an immune and hematopoietic module that contains nine genes and represents phenotypes associated with specific cell types and lineages including macrophage physiology, spleen germinal cell number, granulocyte number, platelet number, T-cell and B-cell proliferation and hematopoiesis. Furthermore, this module exhibited phenotypes associated with susceptibility and resistance to pathogens such as abnormal immune system biology, abnormal class switch recombination and altered rate of infection. Some of the phenotypes in this module, including abnormal somatic hypermutation frequency and lymphoid hyperplasia were related to cancer, perhaps representing the immune surveillance component to the control of tumorigenesis within the body. Finally, some of the phenotypes within this module were associated with the modulation of specific immunologically important molecules such as cytokine secretion, interferon secretion, IgE levels, IgG1levels, and IgM levels. Genes within this module may offer some insight into feline specific immunological and inflammatory disorders.

The fourth module, energy/nutrition and homeostasis consists of six genes and exhibits a number of phenotypes associated with energy production and regulation within cells. Some of these phenotypes include decreased circulating glucose level, decreased oxygen consumption, abnormal gluconeogenesis and increased glucagon. Other phenotypes include endocrine level regulation of the organism such as abnormal body weight and decreased body temperature. Additionally, there were phenotypes associated with diseases of energy metabolism such as diabetes, these phenotypes included insulin resistance, abnormal glucose homeostasis and increased circulating insulin level. These phenotypes provide a context for better understanding of the unique nutritional and energy requirements of the cat.

The fifth module has five genes and encodes a tumorigenesis module associated with the following phenotypes: B-cell derived lymphoma, increased sensitivity to oxidative stress, increased apoptosis, decreased cellular sensitivity to gamma irradiation, increased incidence of ionizing radiation induced tumors, increased tumor incidence, malignant tumors, adenocarcinoma. The genes in this module may provide a useful gene set for investigating the genetic basis of feline lymphoma and carcinoma.

Module six is a sensory systems module, containing five genes, and is associated with the following visual phenotypes: abnormal lens fiber morphology, cataracts, abnormal optic nerve morphology, abnormal eye electrophysiology, abnormal vision, blindness and optic nerve atrophy. Cats exhibit vision related abnormalities under certain nutritional deficiencies; the genes associated with these phenotypes may provide a better understanding of the observed link between feline nutrition and visual function. Other phenotypes within this module include both hyperekplexia and decreased startle response, which may underlie feline adaptations required for successful predation. 
Table 7 Genes Mapped to KEGG Pathways

\begin{tabular}{|c|c|c|}
\hline Pathway Category & Pathway Name & Number of Genes \\
\hline \multirow[t]{15}{*}{ Amino Acid Metabolism } & Alanine and aspartate metabolism & 2 \\
\hline & Arginine and proline metabolism & 3 \\
\hline & Glutamate metabolism & 1 \\
\hline & Glycine, serine and threonine metabolism & 3 \\
\hline & Histidine metabolism & 2 \\
\hline & Lysine degradation & 2 \\
\hline & Methionine metabolism & 1 \\
\hline & Phenylalanine metabolism & 3 \\
\hline & Phenylalanine, tyrosine and tryptophan biosynthesis & 1 \\
\hline & Starch and sucrose metabolism & 1 \\
\hline & Tryptophan metabolism & 6 \\
\hline & Tyrosine metabolism & 7 \\
\hline & Urea cycle and metabolism of amino groups & 1 \\
\hline & Valine, leucine and isoleucine biosynthesis & 2 \\
\hline & Valine, leucine and isoleucine degradation & 3 \\
\hline \multirow[t]{2}{*}{ Biosynthesis of Secondary Metabolites } & Alkaloid biosynthesis II & 1 \\
\hline & Limonene and pinene degradation & 1 \\
\hline \multirow[t]{13}{*}{ Carbohydrate Metabolism } & Aminosugars metabolism & 3 \\
\hline & Ascorbate and aldarate metabolism & 1 \\
\hline & Butanoate metabolism & 2 \\
\hline & Citrate cycle (TCA cycle) & 3 \\
\hline & Fructose and mannose metabolism & 2 \\
\hline & Galactose metabolism & 1 \\
\hline & Glycolysis/Gluconeogenesis & 6 \\
\hline & Glyoxylate and dicarboxylate metabolism & 1 \\
\hline & Inositol phosphate metabolism & 4 \\
\hline & Nucleotide sugars metabolism & 1 \\
\hline & Pentose and glucuronate interconversions & 1 \\
\hline & Pentose phosphate pathway & 3 \\
\hline & Propanoate metabolism & 1 \\
\hline \multirow[t]{4}{*}{ Energy Metabolism } & Methane metabolism & 1 \\
\hline & Nitrogen metabolism & 2 \\
\hline & Oxidative phosphorylation & 15 \\
\hline & Sulfur metabolism & 1 \\
\hline \multirow[t]{8}{*}{ Glycan Biosynthesis and Metabolism } & Glycan structures - biosynthesis 1 & 4 \\
\hline & Glycan structures - biosynthesis 2 & 4 \\
\hline & Glycosphingolipid biosynthesis - lacto and neolacto series & 3 \\
\hline & Glycosylphosphatidylinositol(GPI)-anchor biosynthesis & 1 \\
\hline & Heparan sulfate biosynthesis & 1 \\
\hline & Keratan sulfate biosynthesis & 2 \\
\hline & $\mathrm{N}$-Glycan biosynthesis & 2 \\
\hline & Peptidoglycan biosynthesis & 1 \\
\hline \multirow[t]{5}{*}{ Lipid Metabolism } & alpha-Linolenic acid metabolism & 1 \\
\hline & Androgen and estrogen metabolism & 15 \\
\hline & Arachidonic acid metabolism & 4 \\
\hline & Bile acid biosynthesis & 1 \\
\hline & Biosynthesis of steroids & 3 \\
\hline
\end{tabular}




\begin{tabular}{|c|c|c|}
\hline & Biosynthesis of unsaturated fatty acids & 1 \\
\hline & Ether lipid metabolism & 2 \\
\hline & Fatty acid elongation in mitochondria & 1 \\
\hline & Fatty acid metabolism & 4 \\
\hline & Glycerolipid metabolism & 2 \\
\hline & Glycerophospholipid metabolism & 6 \\
\hline & Linoleic acid metabolism & 1 \\
\hline \multirow[t]{8}{*}{ Metabolism of Cofactors and Vitamins } & Biotin metabolism & 1 \\
\hline & Folate biosynthesis & 3 \\
\hline & Nicotinate and nicotinamide metabolism & 2 \\
\hline & Pantothenate and CoA biosynthesis & 3 \\
\hline & Porphyrin and chlorophyll metabolism & 4 \\
\hline & Retinol metabolism & 2 \\
\hline & Ubiquinone biosynthesis & 2 \\
\hline & Vitamin B6 metabolism & 1 \\
\hline \multirow[t]{3}{*}{ Metabolism of Other Aminoacids } & Aminophosphonate metabolism & 1 \\
\hline & beta-Alanine metabolism & 1 \\
\hline & Glutathione metabolism & 7 \\
\hline \multirow[t]{2}{*}{ Nucleotide Metabolism } & Purine metabolism & 14 \\
\hline & Pyrimidine metabolism & 11 \\
\hline \multirow[t]{8}{*}{ Xenobiotics Biodegradation and Metabolism } & 1- and 2-Methylnaphthalene degradation & 2 \\
\hline & Benzoate degradation via CoA ligation & 1 \\
\hline & Caprolactam degradation & 1 \\
\hline & Drug metabolism - cytochrome P450 & 5 \\
\hline & Drug metabolism - other enzymes & 3 \\
\hline & Geraniol degradation & 1 \\
\hline & Metabolism of xenobiotics by cytochrome P450 & 5 \\
\hline & Styrene degradation & 1 \\
\hline
\end{tabular}

The human orthologs of feline CDNA sequences were used to identify biochemical and metabolic pathways in the KEGG database. A total of 112 cDNA sequences were mapped to 75 pathways. The table indicates the pathway category along with the pathway name and the number of genes mapped from each pathway.

The seventh module is a behavioral/neurological and nervous system set that contains 11 genes. The behavioral phenotypes arising from this module span traits as diverse as motor coordination and balance through learning, memory and gait. Additional phenotypes in this module are associated with emotion and affect as well as vocalization and maternal behavior. Within this module, we identified a number of phenotypes underlying neuronal specific physiological mechanisms such as altered synaptic transmission, altered long term potentiation, abnormal excitatory post synaptic potentials and decreased neurotransmitter release. This module contains a variety of developmentally important nervous system phenotypes having anatomical or histological annotations. These include abnormal brain commissure morphology, abnormal brain development, abnormal embryonic neuroepithelium layer differentiation as well as open neural tube, abnormal cerebellar granule layer, abnormal Purkinje cell layer, small cerebellum, abnormal brain ventricle morphology, abnormal cerebral cortex morphology and abnormal forebrain and hindbrain morphology. Finally, we identified specific CNS phenotypes of clinical importance such as abnormal neuron morphology, abnormal neuron physiology, astrocytosis, brain stem haemorrhage, gliosis and inter cranial haemorrhage.

We chose to focus on a relatively small number of gene-phenotype relationships in order to explore a relatively high resolution picture of important feline phenotypes that may be representative of our cDNA sequences. Our goal was to determine if any of our cDNA sequences were associated with phenotypes that may be of value in understanding the genetic basis of feline specific biology. Our analysis demonstrates that some of our cDNA sequences are indeed associated, through comparative genomics sequence analysis using 


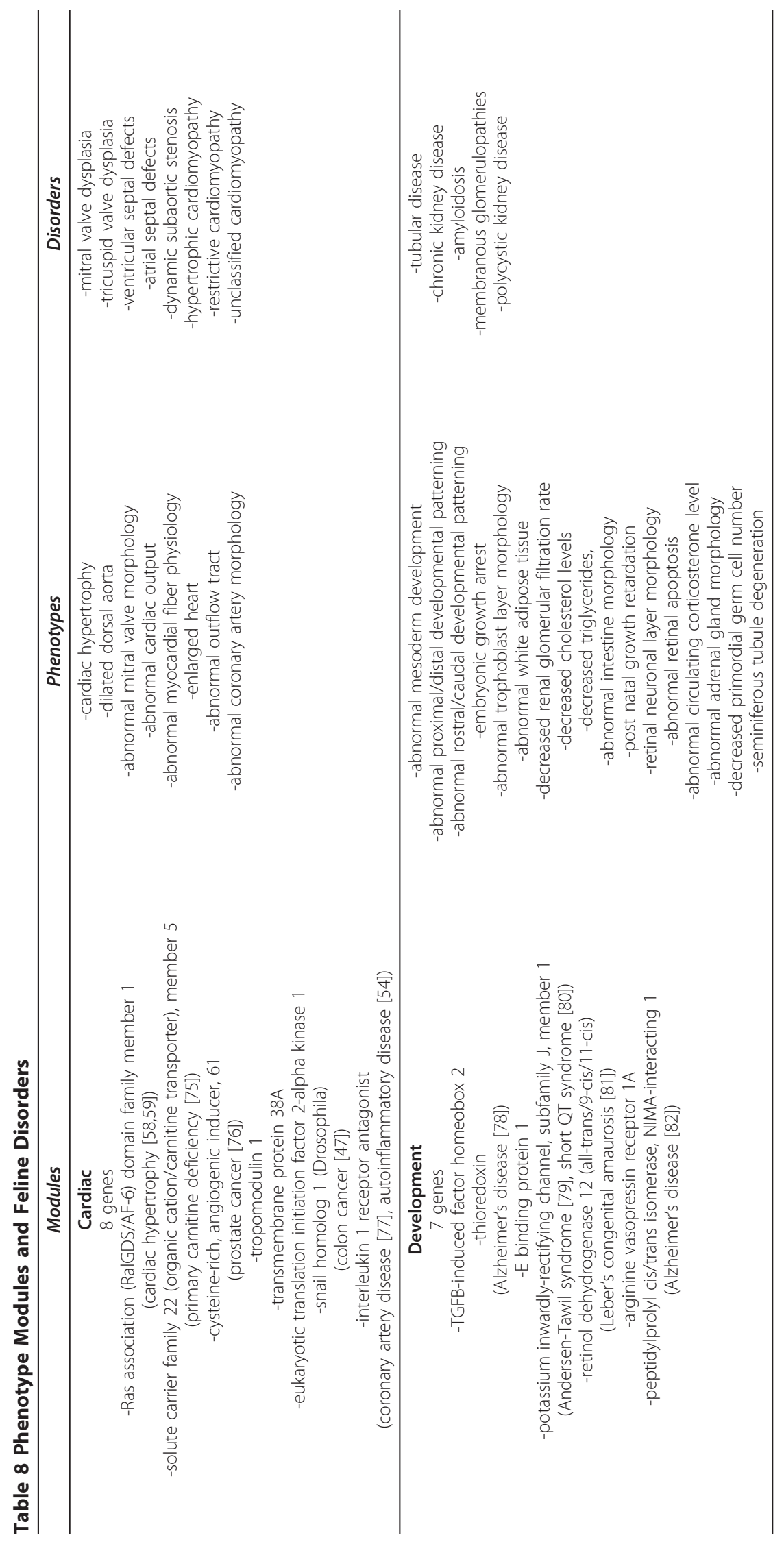




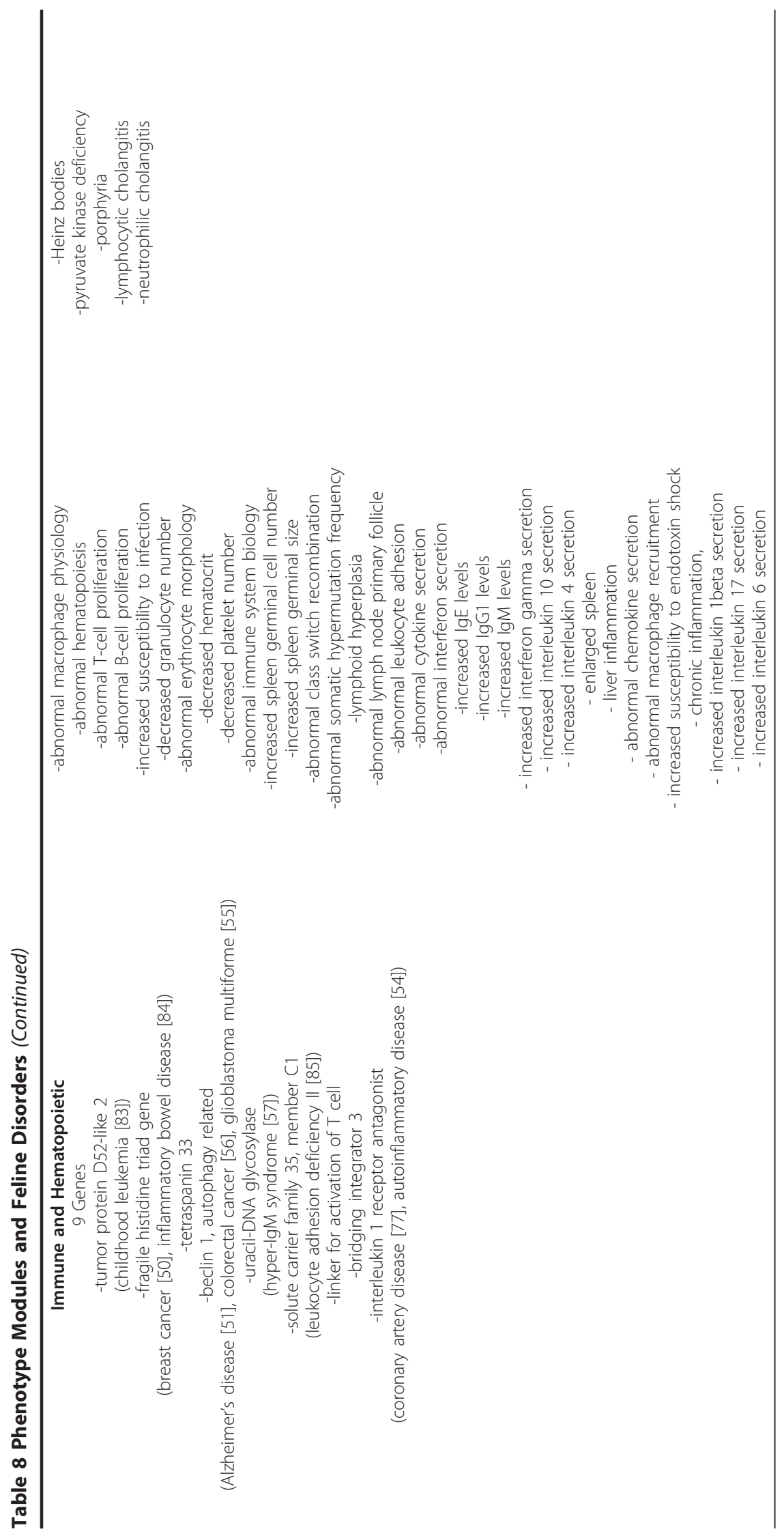




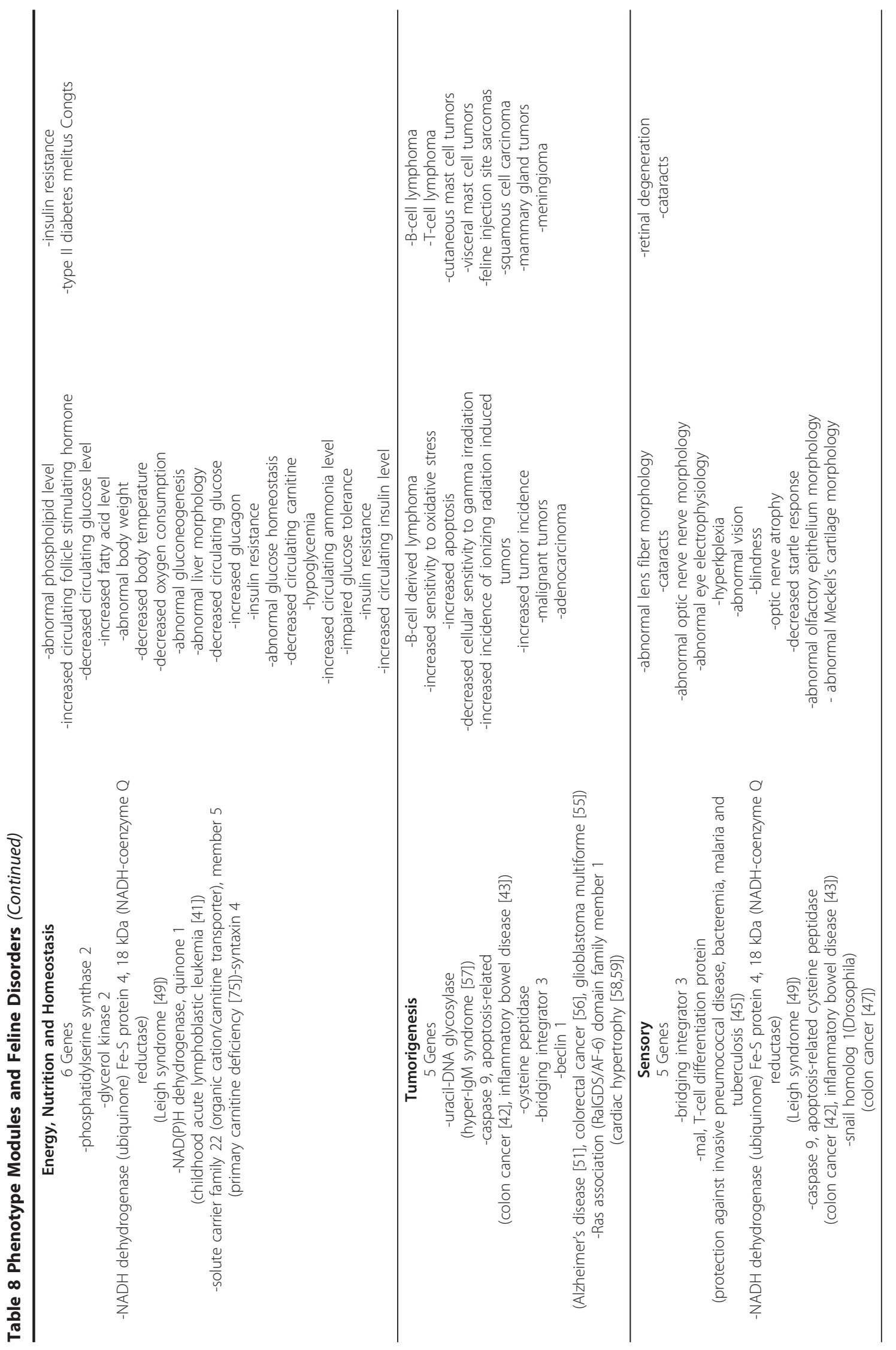




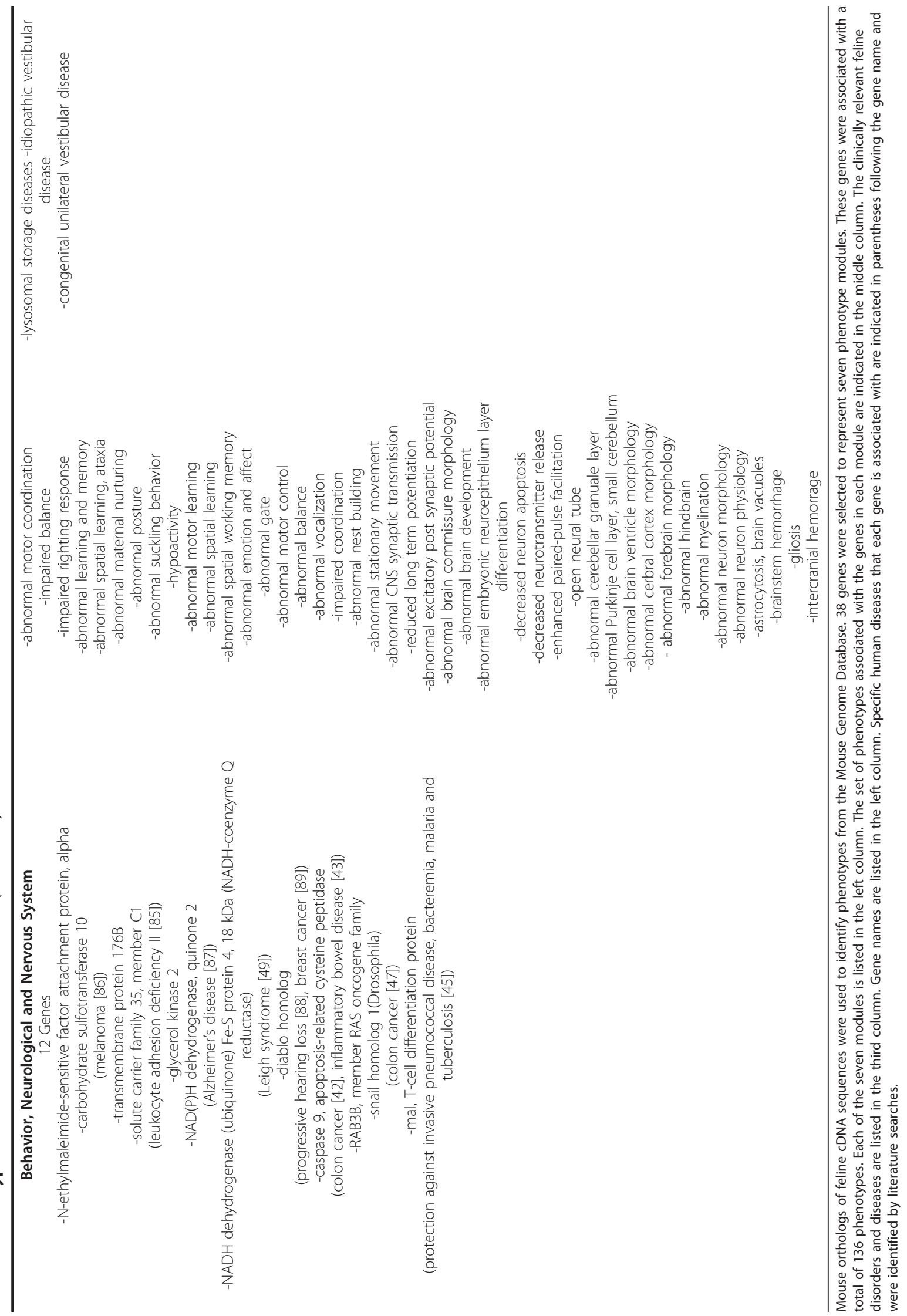


the mammalian phenotype browser database, with phenotypes that are extremely important in feline health and disease. These modules and related genes provide an important and extremely useful candidate gene set for domestic cat functional genomics.

\section{Orthologous OMIM Diseases}

We identified 104 feline cDNA sequences that are orthologs of human genes for which an OMIM (Online Mendelian Inheritance In Man, http://www.ncbi.nlm.nih. gov/omim) disease has been associated (see Table 9 and Additional file 3, Table S3). Within this data set we observe genes implicated in both dilated and familial cardiomyopathy as well as genes associated with oxidative phosphorylation deficiencies and biochemical disorders of amino acid metabolism. The OMIM associated diseases paralleled the phenotype associations we detected and provided additional insight into the clinical and nutritional role of the cDNA sequences we identified.

Within the set of OMIM diseases, we identified biochemical and metabolic diseases such as disorders of oxidative phosphorylation and glycosylation as well as D-2-hydroxyglutaric aciduria, glycogen storage disease, phenylketonuria due to dihydropteridine reductase deficiency and phosphoglycerate kinase 1 deficiency. Among the disease annotations associated with cancers, we found that our cDNA sequences were associated with specific types of OMIM annotations including breast cancer, colon cancer, esophageal carcinoma, lung cancer, pancreatic cancer and ovarian cancer to name a few. We also identified diseases of the sensory systems, such as cataracts and deafness. Finally, we discovered a variety of orthologs of human genes implicated in specific disorders, including Leigh syndrome, Hyper-IgD syndrome, immunodeficiency associated with hyper IgM, Griscelli syndrome, STAR syndrome and Charcot-Marie-Tooth disease, retinitis pigmentosa and generalized epilepsy. Together, these OMIM annotations provide a diverse picture of the genes across diseases and offer a unique context for understanding the role of these cDNA sequences in feline health and disease.

\section{Discussion}

We identified 1227 feline cDNA sequences derived from tissues obtained from ten cats and performed extensive comparative genomics functional analysis to elucidate the computationally derived comparative gene expression analysis patterns, biochemical functions and phenotypes associated with these sequences. Our cDNA sequences and associated comparative and functional analysis provide an initial perspective on feline biology as viewed through our set of 1227 cDNA sequences. Although it is predicted that the number of feline protein coding genes encoded in the cat genome is in the order of 20,000 to 25,000, similar to most other mammalian genomes, the number of known published cat protein coding gene sequences is much lower at 2099 sequences (NCBI databse, 2011). These 1227 cDNA/gene sequences represent a rich set of potential targets for genetic association studies, biologically relevant diets and pharmacologically active compounds which can be developed to enhance the well-being of companion cats worldwide. Additionally, these sequences have value in similar applications for endangered felids.

Our strategy to identify a set of 1227 high quality and high confidence cDNA sequences from feline tissue samples expands the expressed sequence data for domestic cat. Although we initially obtained over 3000 cDNA sequences, we chose to filter our sequences so that the set we describe would be of the most value for the feline genomics community. Specifically, the conservative strategy outlined in Figure 1 resulted in a set of 913 known sequences and 314 novel sequences (1227 sequences in total) of which 914 orthologous clusters across feline, human, dog and mouse were identified (for which 844 were known cDNA sequences and 70 were novel cDNA sequences). The genes corresponding to these 914 orthologs were used as input sequences for a variety of bioinformatics and computational analyses aimed at providing an initial perspective on the physiological and pathological roles of these sequences in feline development, nutrition and health. Although we have identified a number of interesting results using computational and sequence comparison methods, our analysis only identifies the potential roles of these genes based on comparative analysis in other species. However, validating these results and proving the function of these genes will require molecular and biochemical experimental analysis. The results of our inferred expression analysis provide a set of gene expression patterns consistent with the source tissues used for cDNA production. Of the 21 source tissues used as starting material, inferred expression patterns from each anatomical region were detected with greater than 100 genes being associated in each case. It is interesting to note that each of these tissues exhibited relatively high gene expression numbers (i.e., numbers of genes associated with anatomical expression), which is what one would expect if the inferred expression patterns were an accurate representation of the true expression patterns of the source tissues. Tissues such as brain (725 genes), heart (629 genes), pancreas (568 genes) and testis (703 genes) exhibit inferred expression of more than $60 \%$ of the genes encoding our 1227 cDNA sequences. Inferred cellular expression patterns correlated with cell types expected in the source tissues including glial cells and 
Table 9 List of OMIM Diseases

\begin{tabular}{|c|c|}
\hline Disease Name & Disease Name \\
\hline 2-methyl-3-hydroxybutyryl-CoA dehydrogenase deficiency & Glycogen storage disease, type 0 \\
\hline 2-methylbutyrylglycinuria & $\begin{array}{l}\text { Gonadal dysgenesis, } 46 \mathrm{XY} \text {, partial, with minifascicular } \\
\text { neuropathy }\end{array}$ \\
\hline 2-methylbutyrylglycinuria & Griscelli syndrome, type 2 \\
\hline 3-methylglutaconic aciduria, type I & Hawkinsinuria \\
\hline Acyl-CoA dehydrogenase, short-chain, deficiency of & $\begin{array}{c}\text { Hemolytic anemia due to bisphosphoglycerate mutase } \\
\text { deficiency }\end{array}$ \\
\hline Adrenal cortical carcinoma & Homocysteine plasma level \\
\hline Aldolase A deficiency & HPRT-related gout \\
\hline Alzheimer disease-4 & Hyper-lgD syndrome \\
\hline Amyotrophic lateral sclerosis 10 & Hyperleucinemia-isoleucinemia or hypervalinemia \\
\hline Arthrogryposis multiplex congenita, distal, type 1 & Hypervalinemia or hyperleucine-isoleucinemia \\
\hline Bannayan-Riley-Ruvalcaba syndrome & Hypogonadotropic hypogonadism \\
\hline Bartter syndrome, type 2 & Hypokalemic periodic paralysis \\
\hline Beta-ureidopropionase deficiency & Hypomagnesemia, renal, with ocular involvement \\
\hline Birt-Hogg-Dube syndrome, & Hypotrichosis, localized, autosomal recessive \\
\hline Bjornstad syndrome, & Immunodeficiency with hyper IgM, type 4 \\
\hline Breast cancer, sporadic & Leigh syndrome \\
\hline Brugada syndrome 2 & Leukoencephalopathy with vanishing white matter \\
\hline Brunner syndrome & Lipoid adrenal hyperplasia \\
\hline C2 deficiency & Lung cancer \\
\hline C9 deficiency & Mast syndrome, \\
\hline Cardiomyopathy, dilated, 1M, & Megakaryoblastic leukemia, acute \\
\hline Cardiomyopathy, dilated, $1 \mathrm{~N}$ & Mental retardation, $\mathrm{X}$-linked syndromic \\
\hline Cardiomyopathy, dilated, $1 Z$ & Methemoglobinemia due to cytochrome b5 deficiency \\
\hline Cardiomyopathy, familial hypertrophic & Methylmalonyl-CoA epimerase deficiency \\
\hline Carnitine acetyltransferase deficiency & Microphthalmia, syndromic 6 \\
\hline Carnitine deficiency, systemic primary & Mitochondrial complex I deficiency \\
\hline Cataract, posterior polar 2 & Myopathy due to phosphoglycerate mutase deficiency \\
\hline $\begin{array}{c}\text { Cerebral dysgenesis, neuropathy, ichthyosis, and palmoplantar keratoderma } \\
\text { syndrome }\end{array}$ & Myopathy with exercise intolerance, Swedish type \\
\hline Ceroid lipofuscinosis, neuronal 8 & Neuroblastoma \\
\hline Charcot-Marie-Tooth disease, axonal, type 2F & Oral-facial-digital syndrome 1 \\
\hline Charcot-Marie-Tooth neuropathy, X-linked dominant, 1 & Ovarian carcinoma \\
\hline Colon cancer, advanced & Pancreatic cancer \\
\hline Combined oxidative phosphorylation deficiency 2 & Phenylketonuria - dihydropteridine reductase deficiency \\
\hline Combined oxidative phosphorylation deficiency 5 & Phosphoglycerate kinase 1 deficiency \\
\hline Congenital disorder of glycosylation, type IIc & Porphyria cutanea tarda \\
\hline Costello syndrome & Retinitis pigmentosa-46 \\
\hline Cutis laxa, autosomal dominant & Retinitis pigmentosa-46 \\
\hline D-2-hydroxyglutaric aciduria & Ribose 5-phosphate isomerase deficiency \\
\hline Deafness, autosomal recessive 63 & Spastic paraplegia 31 \\
\hline Desmosterolosis & Spondylocostal dysostosis, autosomal recessive 3 \\
\hline Diamond-Blackfan anemia 6 & STAR syndrome \\
\hline Epilepsy, neonatal myoclonic, with suppression-burst pattern & Temperature-sensitive apoptosis, cellular \\
\hline
\end{tabular}


Table 9 List of OMIM Diseases (Continued)

\begin{tabular}{cc}
\hline Esophageal carcinoma, somatic & Transcobalamin II deficiency \\
\hline Galactosemia & Tyrosinemia, type I \\
\hline Generalized epilepsy with febrile seizures & Glutamine deficiency, congenital \\
\hline A tachycardia, catecholaminergic polymorphic, 2
\end{tabular}

A set of 90 human genetic disorders associated with orthologous feline cDNA sequences are listed in the table. The table contains an alphabetical list of the human diseases in two columns. (Additional information including CDNA identifier, ensembl human gene identifier, OMIM identifier and disease name can be found in Additional file 3, Table S3).

neurons (432 genes and 124 genes respectively), retinal pigment epithelium cells (514 genes), and skeletal muscle cells (499 genes). Together, these results provide an expression framework for understanding the roles of these cDNA sequences in feline physiology and pathology. Because greater than $70 \%$ of our cDNA sequences were associated with embryological expression patterns we were not surprised to discover that a significant number of developmental phenotypes were associated with our set of cDNA sequences. Specifically, we identified genes associated with abnormal heart morphology and abnormal cardiac blood flow, abnormal mesoderm development, abnormal developmental patterning and abnormal retinal neuronal layer morphology. These phenotypes are consistent with the expression and role of genes identified in the source tissues selected for cDNA sequencing. The fact that the inferred expression patterns exhibit greater breadth of expression than the starting tissues is in line with the notion that genes tend to be expressed in complex spatial and temporal patterns. It may be the case that the inferred expression patterns include some anatomical, cellular and/or developmental expression patterns which may be false positives, however the overall picture of expression provided by this analysis greatly enhances the value of these cDNA sequences in genomic applications.

Interestingly, our analysis of gene ontology in the context of $\mathrm{dN} / \mathrm{dS}$ values of individual orthologous cDNA sequences provides insight into how the domestic cat is both similar to and differs from other mammals. We detected evidence of negative selection acting on genes associated with microtubules and the actin cytoskeleton, suggesting that genes associated with these cellular structures are fairly well conserved among mammals $[41,42]$. Additionally, we identified gene ontology annotation terms affiliated with the nucleus, the chromosomes and DNA replication exhibiting relatively low values of $\mathrm{dN} / \mathrm{dS}$ along with orthologs associated with transcriptional regulation and translational elongation. Similar values were obtained for genes annotated as Gprotein beta/gamma binding and trans-Golgi network trafficking, vesicle and endoplasmic reticulum compartment membrane and SNARE complex. This is not surprising given that the housekeeping functions of mammalian cells are relatively well conserved. All cells must transmit information from the genome into RNA and protein components in a manner that maintains the appropriate subcellular compartmentalization of molecular functions. Intracellular trafficking that diverges from cellular requirements is likely to exhibit relatively deleterious consequences leading to negative selection compared to cells that function appropriately. Microtubules are involved in cellular integrity, cell motility and cell division; all of these processes are critical for cell viability $[41,43]$.

In comparison to these highly conserved orthologs which mediate the core cellular processes, we detect evidence of considerably less negative selection acting on orthologs associated with transmembrane receptors, apoptotic signals, guanyl-nucleotide exchange factors and GPCR activity. Additionally, we identified evidence of less negative selection among orthologs associated with extracellular spaces, mitochondrial membrane affiliation and integral proteins of the plasma membrane. Unlike the highly conserved orthologs with intracellular functions, these orthologs form the basis of interactions across cells, through the extracellular space into the nucleus and organelles by a variety of signal transduction mechanisms for which multiple paralogous genes exist in each species. Such patterns of selection have been identified by others and represent evolutionary patterns of selection that may be associated with positive selection in different evolutionary lineages [44]. Moreover, these cDNA sequences might encode proteins for which extracellular environment plays a selective role during evolution.

It is well documented that paralogs diverge at a greater rate than orthologs $[45,46]$. Because our analysis did not include the entire set of genes from the cat, we cannot rule out the possibility that some of our orthologs are not true orthologs. It is worthwhile to point out that our analysis included only cat, dog, mouse and human genes which effectively limits the detection of evolutionary selection using the $\mathrm{dN} / \mathrm{dS}$ ratio because some of these species diverged more than 100 million years ago. Nonetheless, it is interesting that others have 
observed similar patterns of divergence in protein networks operating at the cellular periphery and within the extracellular space $[44,47]$.

Our analysis identified orthologs associated with respiratory chain and mitochondria as exhibiting relatively lower levels of negative selection. It is possible that the predatory status of cats resulted in adaptive changes in energy production and oxidative phosphorylation that facilitate the high energy requirements of predation.

It is interesting that we detect evidence of divergence within apoptotic genes in the cat compared to other mammalian species. This may underlie species specific differences in adaptation, such as what might be expected to have happened as obligate carnivores diverged from a common ancestor of omnivores and herbivores. The high protein requirements coupled with enhanced predatory fitness may have co-evolved with differences in cellular response to stress and cellular apoptosis, both within and outside of the brain.

This hypothesis is supported by the metabolic network analysis in GeneGO where the top $25 \% \mathrm{dN} / \mathrm{dS}$ values were associated with metabolic pathways implicated in non-carbohydrate roles. The metabolic network analysis performed with GeneGO demonstrated that genes in the group with smaller $\mathrm{dN} / \mathrm{dS}$ values are associated with metabolic networks most involved in carbohydrate metabolism, while the genes in the larger $\mathrm{dN} / \mathrm{dS}$ value group are in metabolic networks most involved in amino acid metabolism. This suggests that depending on metabolic requirements, the evolution rate may not be the same across all metabolic networks, and obligate carnivores like cats, may exhibit relatively less negative selection acting on genes involved in amino acid metabolism and more neutral selection acting on carbohydrate associated genes. This result is in agreement with the observation that cats exhibit different dietary requirements for amino acids taurine [20], arginine [21], cysteine and, methionine [22]. In contrast to dogs, cats are unable to synthesize taurine from cysteine [34], subsequently, taurine deficiency in cats is associated with a variety of clinically important conditions including cardiac [27] immune [28], neurological [29], platelet [30], reproductive [31] and retinal [32] dysfunctions. Additionally, cats exhibit rapid onset of ammonia toxicity resulting from arginine deficiency and, in severe cases, may die within 24 hours $[23,48]$.

Through the use of KEGG pathway annotation, we identified domestic cat genes involved in a variety of amino acid related pathways including the metabolism of alanine, aspartate, arginine, proline, glutamate, glycine, serine, threonine, histidine, lysine, methionine, phenylalanine, tyrosine and tryptophan. We identified specific pathways in amino acid metabolism, which tend to differ between obligate carnivores and omnivorous mammals [49]. These include six genes involved in tryptophan metabolism which are of value for cats because they are unable to synthesize niacin from tryptophan, as compared to omnivores [48]. Additionally we identified three genes involved in arginine metabolism, which is an essential amino acid in cats [26]. We identified genes involved in glutamate metabolism, which may provide insight into the metabolic consequences of the low levels of ornithine produced from glutamate in cats [48].

We also identified genes associated with pathways underlying lipid metabolism, including genes participating in biochemical pathways of linoleic, alpha-linoleic acid and arachidonic acids, which is important and noteworthy because cats cannot use linoleic acid for the biosynthesis of arachidonic acid [48]. Further analysis of these genes may provide clues about feline biochemistry associated with arachidonic acid which may be important in feline reproduction [36]. Finally, we identified genes involved in the metabolism of retinol, which represent another very important gene set because cats are unable to synthesize retinol from beta-carotene [50].

The metabolism and biosynthesis of cofactors, vitamins and glycans is important in the nutrition and health of animals. Within these biochemical pathways, we identified three genes associated with folate metabolism, seven genes involved in glutathione metabolism and two genes associated with keratin sulfate biosynthesis, two genes associated with $\mathrm{N}$-glycan biosynthesis and three genes associated with pathothenate and CoA biosynthesis. Some of these genes may provide value as important biological markers for monitoring oxidative stress, apoptosis and immune function in cats [51].

Collectively, many of these genes and their associated pathways are important for feline health and nutrition because they represent biochemical processes that cats have adapted to accommodate the narrow dietary range of an obligate carnivore in contrast to omnivorous mammals. The subsequent characterization of these genes and pathways may provide a genomic foundation for understanding how obligate carnivores differ from other animals in both health and disease.

Our functional and evolutionary analysis suggests that through divergent evolutionary trajectories, different species evolve slightly different biochemical processes of cells, tissues and organs that contribute to the manifestation of species specific adaptations and disorders. The domestic cat is known to suffer from a number of hereditary diseases, many of which have counterparts in other species like humans and dogs [52]. As part of our investigation into the biological significance of our cDNA sequences, we employed a comparative genomics approach to discover the phenotypes associated with these sequences. Our approach leveraged the 
mammalian phenotype ontology that has been developed as part of the mouse genome database [40]. We decided to select a relatively small number of genes for which a considerable number of important phenotypes may be associated.

Our phenotype data was obtained from previously published mouse phenotyping studies using transgenic or knockout mice. Subsequently, they should be considered as related to, rather than exactly, the true phenotypes that might arise in the cat. Because our method relies upon orthologous relationships between cat and mouse genes, it is worthwhile to point out that inaccurate mappings between orthologs may lead to inaccurate predictions of phenotypes. Furthermore, as we have described throughout this paper, the cat exhibits some strong similarities to general biological processes that are shared with mammals. The cat also has well documented differences when compared to omnivorous animals. Therefore, one must consider the phenotype analysis as a general thematic picture of the functional consequences of our cDNA sequences rather than as a one-to-one mapping of gene-phenotype associations within our cDNA sequences.

We identified seven phenotypic modules exhibiting 136 phenotypes arising from only 38 genes. Many of the genes we identified exhibit numerous phenotypes, both within and across modules. Such pleiotropic effects underlie the complexity of mammalian genomes and provide context for future genomic studies. We selected these gene-phenotype associations to provide a detailed, but yet tractable picture of how our cDNA sequences might map onto anatomical and physiological traits.

Within the cardiac module, we identified eight genes associated with phenotypes relating to cardiac disease in cats. Some of the genes within this module include tropomodulin 1 , snail homolog 1 and an interleukin receptor antagonist. This module includes phenotypes of cardiac hypertrophy and mitral valve defects, both of which are known hereditary diseases in cats [53]. These genes provide examples of the types of phenotypes that might arise from perturbations of cat genes underlying inherited feline cardiac diseases, such as aortic stenosis, atrial-septal defect, mitral valve displasia, tetralogy of Fallot and ventricular-septal defect [53,54].

Our developmental module consists of seven genes and includes a TGFbeta induced homeobox transcription factor as well as the signaling molecule argininevasopressin. The phenotypes associated with this module include developmental patterning across both the proximal/distal axis and the rostral/caudal axis. The phenotypes also include cellular specification and patterning such as mesoderm development, trophoblast layer morphology and adipose tissue differentiation, to name a few. Domestic cats exhibit a variety of developmental defects, such as polydactyly, hip dysplasia, sacrococcygeal dysgenesis, portocaval shunt, open central fontanel, open lateral fontanel and thoracic hemivertebra [54-57]. The cDNA sequences we describe may include genes that are responsible for abnormal developmental conditions in domestic and endangered felids.

We identified a sensory module, which contains five genes such as NADH dehydrogenase (ubiuinone) Fe-S protein 4 and caspase 9 apoptosis-related cysteine pepidase. This module includes the phenotypes of cataracts, blindness and optic nerve atrophy. Examples of inherited sensory system disorders in the domestic cat include cataracts, corneal dystrophy (stromal and endothelial), progressive retinal atrophy and glaucoma [58]. The overlap between retinal and ocular phenotypes and inherited feline diseases suggests that there are specific genomic regions, represented by our cDNA sequences, which may include aspects of the genetic mechanisms of these debilitating diseases in cats. It is interesting to note that our sensory module includes genes involved in energy production. This is not surprising as retinal tissue is known to exhibit relatively high energy requirements and depletion of energy in this tissue has been associated with blindness and other vision defects [50].

Within our energy and homeostasis module, we identified genes like glycerol kinase 2, NAD $(\mathrm{P}) \mathrm{H}$ dehydrogenase quinone 1 and $\mathrm{NADH}$ dehydrogenase (ubiquinone) Fe-S protein 4 . The phenotypes within this module are associated with traits of clinical and adaptive importance in the cat. For example, our comparative phenotype analysis identified phenotypes of insulin resistance, increased circulating insulin level and impaired glucose tolerance; traits associated with the feline hereditary disease of diabetes mellitus [59]. This module also contains phenotypes such as abnormal gluconeogenesis, increased glucagon, abnormal glucose homeostasis and increased circulating ammonia level, which are important in felid nutrition as cats use gluconeogenesis as a predominant form of energy production and are susceptible to ammonia toxicity $[17,18]$. The genes in this module are of value in exploring some of the fundamental metabolic and biochemical differences between obligate carnivores and omnivores. Moreover, these genes may provide a genomic basis for specific diets that can reduce the incidence of feline disorders associated with specific nutritional deficiencies.

Within other modules, we identified phenotypes associated with cancer, such as increased tumor incidence, malignant tumors and B-cell derived lymphoma which may provide clues to the genetic susceptibility cats have for hereditary lymphoma [60]. Among the behavioral phenotypes within the nervous system module, we 
identified a number of traits that may represent predator specific adaptations of cats. For example, we identified cDNA sequences associated with spatial learning, balance, righting response, gate and motor coordination; traits that are almost synonymous with cats and of extreme adaptive value for an apex hyper predator.

The comparative genomics analysis of OMIM diseases within our cDNA sequence data set provides a final perspective on the importance of our reported sequences in the health of domestic cats. Many of the diseases identified in the OMIM mapping are also represented by phenotypes within the modules. This independent annotation demonstrates that our analysis converges even though OMIM analysis leverages human orthology relationships and the phenotype analysis leverages murine orthology relationships. It is worth noting the limitation of sequence based comparative genomics approaches. They can provide considerable insight into the functional role of our cDNA sequences, but must ultimately be proven through focused and carefully designed genomics studies in cats. Nonetheless, our cDNA sequences and associated analysis provide considerable value through the identification of many interesting clinically and nutritionally relevant feline genes.

The set of diseases and phenotypes provides a starting point for candidate gene approaches and for the selection of biomarkers for monitoring nutrition and health. By combining diverse types of annotation, we can better understand the function of a given gene in a breadth of tissues and organ systems and of the biological processes it is involved in the organismal level, as well as its role in disease. For example, we identified genes associated with expression in the heart, and with a number of cardiac phenotypes, including cardiac hypertrophy, abnormal outflow tract and abnormal mitral valve morphology, as well as the OMIM disease annotation of dilated cardiomyopathy. These are of direct relevance to feline disease, since hypertrophic cardiomyopathy is a common clinical concern in cats [53].

The recent development of a 70,000 SNP feline bead array by Hill's Pet Nutrition and the Morris Animal Foundation provides an important and powerful resource for conducting gene association studies in the domestic cat, and related endangered species. However, even in the absence of whole-genome genetic association approaches, our characterization of these 1227 cDNA sequences provides an extremely valuable resource for candidate gene approaches aimed at investigating the genetic basis of feline phenotypes. It will be interesting to see how our comparative and functional analysis of these $1227 \mathrm{cDNA}$ sequences compares to the data produced from high throughput sequencing and future genetic studies within and across different breeds in the domestic cat. It is likely that some of our functional annotations may turn out not to hold, and it is equally likely that some of them will. Through collaborative efforts, it will be possible to begin unravelling the genetic mechanisms underlying feline health and disease.

\section{Conclusions}

We report the identification of 1227 feline cDNA sequences of which, 913 correspond to higher quality versions of public feline sequences and 314 correspond to novel feline sequences for which no known public sequence data exists. Our comprehensive functional analysis identified a number of physiologically important biochemical pathways that these sequences are involved in as well as of the developmental, clinical and nutritional relevant phenotypes they are associated with.

\section{Methods}

\section{Construction of feline tissue specific cDNA libraries}

The study protocol was reviewed and approved by the Institutional Animal Care and Use Committee. All cats were immunized against feline panleukopenia, calici, rhinotracheitis, and rabies. Cats were housed with $10-12$ other cats and food was continuously available throughout the day until their daily caloric requirements were consumed. Cats were housed in spacious rooms with natural light that varies with seasonal changes. Cats experienced behavioral enrichment through interactions with each other, by daily interaction and play time with caretakers, large windows and sun porches to watch the natural landscape and access to toys. At the end of their natural life, cats were euthanized for humane purposes and tissues were stored at $-80 \mathrm{C}$.

Total RNA was purified from 21 feline tissues (brain, kidney medulla/cortex, spleen, heart, liver, lung, skeletal muscle, thyroid gland, lymph node, pancreas, adrenal gland, tongue, colon, mammary gland, neonatal thymus, brain and testes) collected from 10 domestic shorthaired cats postmortem, three cell lines derived from kidney, brain, lung, and 1 tissue pool using standard procedures as described in [48]. The purity and integrity of each RNA sample was assessed by spectrophotometry and gel electrophoresis. Forty normalized cDNA libraries were constructed by Agencourt Inc. (BeckmanCoulter Genomics), 22 with standard inserts $(1.2 \mathrm{~kb})$ and 18 with long inserts $(>4 \mathrm{~kb})$. The first and second cDNA strands were synthesized using optimized methods, and cDNAs were size selected prior to cloning. The size-selected cDNAs were directionally cloned into the pAGEN vector by polishing and restriction digest, creating a 5' blunt end and a 3' overhang.

Each cDNA library was subsequently tested for specific quality control measures (average insert size, number of independent clones and percentage of recombinant 
clones), and normalized to reduce the proportion of highly abundant mRNAs. Normalization was performed by dividing each library into two populations, using the first for in vitro transcription of biotinylated RNA, and the second to generate single stranded phagemid DNA. The two populations were then mixed, and self-hybridized DNA-RNA molecules corresponding to overrepresented mRNAs were removed. The remaining single stranded DNA molecules were primed for second strand synthesis and the resulting clones were transformed into bacteria, yielding the normalized libraries.

\section{Sequencing of feline cDNA libraries}

Plasmids were purified from each library using a largescale automated protocol, the SprintPrep ${ }^{\circledR}$ Solid Phase Reversible Immobilization procedure. Sequencing reactions were performed in 384-well plates using BigDye ${ }^{\circledR}$ Version 3.1 direct cycle sequencing (Applied Biosystems, CA). Sequencing reactions were purified using the CleanSeq ${ }^{\circledR}$ dye-terminator removal kit (Agencourt, Inc.), and resolved by capillary electrophoresis using the ABI3730 Genetic Analyzer (Applied Biosystems, CA). Sequencing reads were processed using Phred and quality scores for each run were monitored using the Agencourt, Inc. Galaxy LIMS system. Sequencing of these cDNA libraries yielded a total of 919,676 EST reads.

\section{Data Management and Analysis}

The sequence data, annotation data and the data resulting from sequence analysis were loaded into the MySQL relational database version 5 to facilitate data management and analysis [61].

\section{Sequence Filtering and Ortholog Detection}

A set of 3035 full length feline cDNA sequences were obtained from the analysis of the sequencing data and used to identify a set of high confidence cDNA sequences. All cDNA sequences were translated in 6 reading frames and the longest protein coding sequence obtained was noted. These cDNA and protein sequences were clustered using blast to identify a set of nonredundant nucleotide and non-redundant protein sequences using a stringency of $95 \%$ or greater as criteria for identifying redundant sequences. For each cluster, the longest representative sequence was chosen as the non-redundant representative. The intersection of non-redundant nucleotide sequences and non-redundant protein sequences was used as the set of non-redundant sequences.

The BLAST programs, blastp and blastn $[62,63]$, were run with the non-redundant full length feline sequences as query and the target species sequences downloaded from ENSEMBL ftp://ftp.ensembl.org/pub/current/fasta/ [36] as subject sequences. The subject sequences for each of the four species (dog, cat, human and mouse) were: Homo_sapiens.GRCh37.60.cdna.all.fa (containing 147,141 sequences), Homo_sapiens.GRCh37.60.pep.all.fa (containing 81,968 sequences), Mus_musculus. NCBIM37.60.cdna.all.fa (containing 82,508 sequences), Mus_musculus.NCBIM37.60.pep.all.fa (containing 50,959 sequences),

Canis_familiaris.BROADD2.60.cdna.all.fa (containing 27,301 sequences),

Canis_familiaris.BROADD2.60.pep.all.fa (containing 25,559 sequences),

Felis_catus.CAT.60.cdna.all.fa (containing16,332 sequences) and

Felis_catus.CAT.60.pep.all.fa (containing 15,048 sequences). Because the human sequence sets contain the greatest number of target sequences, 147,141 nucleotide sequences and 81,968 protein sequences, the set of non-redundant sequences were mapped to the human sequences. Additionally, the full length sequences were mapped to the set of known feline cDNA and protein sequences in order to classify the full length non-redundant feline sequences as either known or novel, where known indicates that the sequence is represented by a feline sequence in the public ensembl transcript/protein sequence data while novel indicates that the sequence does not have a representative transcript or protein sequence in the ensembl data set.

Because the public feline data does not contain all of the protein coding genes, it was not possible to perform an ortholog search using the standard reciprocal best hit approach. Instead, the blast results were filtered using an iterative heuristic process of selecting blast hits with specific match lengths, gaps, number mismatches and percent identity. In total, eight iterative steps were performed beginning with the most stringent and ending with the least stringent. Each step identified a set of qualifying non-redundant full length sequences. The first and most stringent step imposed the requirement that the blast match_length must be equal to the smallest of the two sequences (query or subject) and the number of mismatches $=0$, number of gaps $=0$, and the percent identity $\geq 99 \%$. A second filter was used to add additional sequences to the results of the first step, and any sequences that had not been identified in the first step were added to the set of results. The second step used a blast match_length ratio of $\geq 0.99$, number mismatches $=0$, number gaps $=0$ and percent identity $\geq 99 \%$. A third step identified additional sequences that satisfied the third step criteria and for which the first two steps did select the non-redundant full length sequence. The third step criteria were blast match length ratio $\geq 0.87$, number of mismatches $\leq 4$, number of gaps $=0$, and percent identity $\geq 99 \%$. The iterative process continued for a total of eight steps with each 
subsequent step relaxing the filtering criteria in order to identify sequences that were not identified in the previous step. Fourth step criteria were blast match length ratio $\geq 0.725$, number mismatches $\leq 5$, number of gaps $=0$, and percent identity $\geq 99 \%$. Fifth step criteria were blast match length $\geq 0.69$, number mismatches $\leq 4$, number gaps $\leq 1$ and percent identity $\geq 99 \%$. Sixth step criteria included blast match length $\geq 0.625$, number mismatches $\leq 8$, number of gaps $\leq 1$, and percent identity $\geq 98 \%$. Seventh step criteria included blast match length ratio $\geq 0.575$, number mismatches $\leq 13$, number gaps $\leq 2$ and percent identity $\geq 97 \%$. The eighth step criteria were blast match length $\geq 0.52$, number mismatches $\leq 12$, number of gaps $\leq 2$ and percent identity $\geq 97 \%$.

The resulting set of non-redundant full length sequences were considered to represent the high quality feline cDNA and protein sequences. These high quality sequences which mapped to a known public feline sequence were used to generate global nucleotide and protein alignments using the partial order alignment software POA http://bioinfo.mbi.ucla.edu/poa2/ POA_Online/Align.html[64,65]. All alignments were manually inspected to ensure that each non-redundant full length feline sequence mapped to the correct public feline sequence.

\section{Comparative Expression Analysis}

In order to infer anatomical and cellular expression patterns of our sequences, four expression annotation files were downloaded from the public biomart http://www. biomart.org[66] web server. Because we mapped our sequences to their corresponding human orthologs, we downloaded the human biomart egenetics annotation data sets mapped on top of the ensembl gene 60 version human gene identifiers. The four annotation sets we obtained included human ensembl gene identifiers mapped to (1) a set of anatomical terms, (2) a set of cell types, (3) a list of pathological terms and (4) a list of developmental stages ranging from weeks to years.

Although our sequences represent a subset of gene products, we found value in identifying the spectrum of expression patterns these sequences may exhibit beyond the tissue libraries that we used. The mapping was accomplished by loading each of the four gene expression annotation files into the MySQL relational database and performing SQL queries that joined these expression tables to our orthologous gene set using the ensembl human gene identifier.

\section{dN/dS Codon Substitution Rate Calculations}

In order to better understand the evolutionary relationships between the feline cDNA sequences and the orthologous sequences in dog, human and mouse, we calculated $\mathrm{dN} / \mathrm{dS}$ values for orthologous sequences across the different species. Phylogenetic Analysis by Maximum Likelihood (PAML version 4.4) software was used to run the codon stats using the "codeml" program. Codon stats were computed where it was possible (DNA and protein sequence availability for the orthologs) with basic model (NSSites $=0) \omega=d N / d S$, the ratio of nonsynonymous/synonymous substitution rates

The $\omega$ ratio is a measure of natural selection acting on the protein. Simplistically, values of $\omega<1,=1$, and $>1$ means negative purifying selection, neutral evolution, and positive selection respectively. PAL 2NAL [67-69] was used to create codon alignments between the cDNAs and the proteins to input to PAML program which computes the $\mathrm{dN}, \mathrm{dS}$ and $\omega$ ratio. Codon substitution rate data was loaded into the MySQL relational database and used to assess the evolutionary pressure exerted on specific groups of genes. The gene groups were derived from other annotation types, such as gene ontology and phenotype annotation results.

\section{Gene Ontology Annotation}

Gene ontology annotation was added to the set of orthologous sequences via comparative sequence analysis. Because the orthologous sequences were already mapped to the human transcripts and proteins, we decided to download the gene ontology annotation files corresponding to biological process, molecular function and cellular localization in order to annotate the nonredundant full length feline sequences with gene ontology terms [70]. The gene ontology annotation files linking the gene ontology terms to the ensembl human gene identifiers were obtained from biomart http://www. biomart.org. Each feline sequence we identified was annotated with all of the gene ontology terms associated with the orthologous human gene. In this manner, we were able to identify a larger set of gene ontology annotations per feline gene than we could have accomplished if we limited the annotation mapping to only the feline cDNA sequences we identified. Through this greedy algorithm, we were able to gain a more comprehensive understanding of the genes we identified. SQL queries in MySQL database were used to map the human gene ontology annotation terms to the orthologous feline genes encoding the cDNA sequences we identified.

\section{GeneGO Metabolic Network Analysis}

Metabolic networks of feline sequences (using ENSEMBL id to upload) were performed using the MetaCore software (GeneGO, St. Joseph, MI). MetaCore identifies networks based on a manually curated database containing known molecular interactions, functions, and disease interrelationships. The networks are identified by the probability that a random set of genes 
the same size as the input list would give rise to a particular mapping by chance. Therefore, an enrichment of biological relevant pathways or networks can be found.

\section{KEGG Pathway Annotation}

Pathway associations were identified using a comparative genomics approach. Because our orthologous sequences were mapped to human orthologs, it was possible to use the human pathway association information to map the pathways on the orthologous feline sequences. This was accomplished using SQL queries to join the KEGG http://www.genome.jp/kegg/pathway. html[71] and Biocarta http://www.biocarta.com/genes/ index.asp pathway data [72] that has been associated with human ensembl gene identifiers with feline gene identifiers. Additional pathways were identified using the David Bioinformatics Database http://david.abcc. ncifcrf.gov/[73] through a gene set search using the ensembl gene identifiers for the set of human orthologs of the feline sequences we identified.

\section{Comparative Phenotype Mapping}

Gene specific phenotype annotation derived from mouse knockouts and/or transgenic strains is compiled and made publicly available at the Mouse Genome Database http://www.informatics.jax.org/[40]. The phenotype annotation is structured within the mammalian phenotype ontology which provides an acyclic graph of mammalian morphological and physiological phenotypes. Because the mouse phenotype data is associated with each mouse gene, it was possible to link the mammalian phenotype ontology to the feline nonredundant full length sequences through a two step process. First, the mammalian phenotype annotations linked to mouse gene identifiers were obtained and loaded into the MySQL database. Next, the appropriate SQL query was performed which created a table that joined the phenotype information with our feline sequence data. The resulting phenotype annotations on top of the feline orthologous gene set provide an additional mechanism for understanding the role of these cDNA sequences in cat development, health and disease.

\section{OMIM Disease Mapping}

A comparative genomics map of our feline sequences annotated with the OMIM http://www.ncbi.nlm.nih.gov/ omim[74] disease information was generated using two different approaches. The first approach utilized MIM disease data that was produced from biomart and anchored to the human ensembl gene identifiers. The resulting annotation file was loaded into the relational database and an appropriate SQL query was used to connect the disease information to the feline sequences through the orthologous relationships that were previously determined. The resulting mapping provided formal associations between feline cDNA sequences and OMIM disease information http://www.ncbi.nlm.nih. gov/omim.

A second method of mapping the feline sequence data to the OMIM data was used to improve the set of OMIM annotated feline cDNA sequences. Specifically, the set of human ensembl gene identifiers corresponding to the orthologs for the feline cDNA sequences were used to query the David Bioinformatics database for OMIM disease information. The resulting file downloaded from the David Database contained human ensembl gene identifiers and OMIM disease identifiers. This file was loaded in the MySQL database and linked with the non-redundant feline cDNA sequences using an appropriate SQL query.

\section{Additional material}

\begin{abstract}
Additional file 1: The cDNA and protein sequences and other information corresponding to the 1227 identified feline sequences This table lists both the cDNA and protein sequences and corresponding lengths for each of the 1227 feline sequences we identified, along with the designation novel (314 sequences) or known (914 sequences). Sequence Identifier (unique identifier for each of the 1227 nonredundant feline sequences). Status (known denotes sequences that map to public feline sequences and novel denotes sequences with no identity to public feline sequences). cDNA Sequence Length (nucleotide length of cDNA sequence). cDNA Sequence (nucleotide sequence of cDNA). Protein Sequence Length (amino acid length of protein sequence). Protein Sequence (protein sequence corresponding to longest translation
\end{abstract} product of the CDNA).

Additional file 2: Sequences and other information on orthologous sequences from the dog, human and mouse. This table contains the 914 orthologous sequences (844 known and 70 novel) and the corresponding ensembl gene, transcript and protein identifiers for the dog, human and mouse orthologs. Status (known denotes sequences that map to public feline sequences and novel denotes sequences with no identity to public feline sequences). Symbol (gene symbol). Title (gene title). Sequence Identifier (unique identifier for each non-redundant feline sequence). Cat Gene Id (cat ensembl gene identifier for sequences designated as known). Cat Transcript Id (cat ensembl transcript identifier for sequences designated as known). Cat Protein ld (cat ensembl protein identifier for subset of sequences designated as known). Dog Gene Id (ensembl gene identifier of dog ortholog). Dog Transcript Id (ensembl transcript identifier of dog ortholog). Dog Protein Id (ensembl protein identifier of dog ortholog). Human Gene Id (ensembl gene identifier of human ortholog). Human Transcript Id (ensembl transcript identifier of human ortholog). Human Protein Id (ensembl protein identifier of human ortholog). Mouse Gene Id (ensembl gene identifier of mouse ortholog). Mouse Transcript ld (ensembl transcript identifier of mouse ortholog). Mouse Protein Id (ensembl protein identifier of mouse ortholog).

Additional file 3: Feline Genes Mapped to OMIM Diseases. This table contains a set of 104 feline cDNA sequences that were mapped to their corresponding human orthologs and the associated OMIM diseases. The first column indicates the cDNA identifier, the second column contains the ensembl human gene identifier for the orthologous human gene, and the third and fourth columns contain the OMIM disease identifier and the disease name respectively. Sequence Identifier (unique identifier for each non-redundant feline sequence). Human Gene Id (ensembl gene identifier of human ortholog). OMIM Identifier (OMIM id for a 
specific human disease). Disease Name (the name of the disease from the OMIM database).

\section{Acknowledgements}

This work was supported by Hills Pet Nutrition, Inc. The authors would like to thank Dr. Steve Henriksen at Western University of Health Sciences for his help in providing the research infrastructure needed to complete this project. The authors would like to thank Dr. Teresa Morishita, Dr. Steve Waldhalm and Dr. Phil Nelson for freeing KJ from teaching responsibilities and providing additional research time needed to complete this project. The authors wish to thank Dr. Barry Watson for facilitating the creation of the Western University of Health Sciences comparative genomics partnership with Hills Pet Nutrition, Inc.

\section{Author details}

${ }^{1}$ College of Veterinary Medicine, Western University of Health Sciences, 309 East Second Street Pomona California, 91766, USA. ${ }^{2}$ The Applied Genomics Center, Graduate College of Biomedical Sciences, Western University of Health Sciences, Pomona California 91766, USA. ${ }^{3}$ Pet Hill's Pet Nutrition, Pet Nutrition Center, 1035 NE 43rd Street Topeka, KS 66617, USA. ${ }^{4}$ College of Osteopathic Medicine of the Pacific, Western University of Health Sciences, Pomona California 91766, USA.

\section{Authors' contributions}

All authors have read and approved the final manuscript. $\mathrm{KJ}$ co-developed the experimental strategy, performed comparative genomics analysis of CDNA sequences and wrote the manuscript. SBM performed dN/dS calculations, managed orthologous data sets, provided critical review of results and contributed to manuscript. XG performed GeneGO analysis, provided critical review of results and contributed to manuscript. KM provided interpretation and relevance of comparative genomics annotation data sets and contributed to manuscript. LM provided interpretation and clinical relevance of comparative genomics annotation data sets and contributed to manuscript. PB provided interpretation and clinical relevance of comparative genomics annotation data sets and contributed to manuscript. JAB responsible for the CDNA sequencing data, provided critical review of experimental approach and contributed to manuscript. SWA co-developed the experimental strategy, responsible for the cDNA sequencing data, managed the project and coordinated data production and manuscript preparation.

\section{Competing interests}

Western University of Health Sciences received funding from Hill's Pet Nutrition to support Kl's time on this project.

Received: 20 April 2011 Accepted: 18 January 2012

Published: 18 January 2012

\section{References}

1. Carnivora: Dogs, cats, bears, raccoons, weasels, mongooses, hyenas, seals, walruses, etc.[http://tolweb.org/Carnivora/15971/2000.01.01].

2. Tarditi CR, Grahn RA, Evans JJ, Kurushima JD, Lyons LA: Mitochondrial DNA sequencing of cat hair: an informative forensic tool. J Forensic Sci 2011, 56(Suppl 1):S36-46.

3. Bradshaw JW, Goodwin D, Legrand-Defretin V, Nott HM: Food selection by the domestic cat, an obligate carnivore. Comp Biochem Physiol A Physiol 1996, 114(3):205-209.

4. Batchelor DJ, Al-Rammahi M, Moran AW, Brand JG, Li X, Haskins M, German AJ, Shirazi-Beechey SP: Sodium/glucose cotransporter-1, sweet receptor, and disaccharidase expression in the intestine of the domestic dog and cat: two species of different dietary habit. Am J Physiol Regul Integr Comp Physiol 2011, 300(1):R67-75.

5. O'Brien SJ, Johnson WE: The evolution of cats. Genomic paw prints in the DNA of the world's wild cats have clarified the cat family tree and uncovered several remarkable migrations in their past. Scientific American 2007, 297(1):68-75.
6. Johnson WE, Eizirik E, Pecon-Slattery J, Murphy WJ, Antunes A, Teeling E, O'Brien SJ: The late Miocene radiation of modern Felidae: a genetic assessment. Science 2006, 311(5757):73-77.

7. Mota P, Amaral S, Martins L, de Lourdes Pereira M, Oliveira PJ, RamalhoSantos J: Mitochondrial bioenergetics of testicular cells from the domestic cat (Felis catus)-a model for endangered species. Reprod Toxicol 2009, 27(2):111-116.

8. Pettersson LG, Perfiliev S, Zotova E, Lundberg A: Role of claws and pads in taking and holding food in cats. Neurosci Res 1998, 31(4):343-346.

9. Perfiliev $S$, Pettersson LG, Lundberg A: Control of claw movements in cats. Neurosci Res 1998, 31(4):337-342.

10. Populin LC, Yin TC: Pinna movements of the cat during sound localization. J Neurosci 1998, 18(11):4233-4243.

11. Stecker GC, Mickey BJ, Macpherson EA, Middlebrooks JC: Spatial sensitivity in field PAF of cat auditory cortex. J Neurophysiol 2003, 89(6):2889-2903.

12. Las L, Shapira AH, Nelken I: Functional gradients of auditory sensitivity along the anterior ectosylvian sulcus of the cat. J Neurosci 2008, 28(14):3657-3667.

13. Jeffery N, Cox PG: Do agility and skull architecture influence the geometry of the mammalian vestibulo-ocular reflex? J Anat 2010, 216(4):496-509.

14. Homman-Ludiye J, Manger PR, Bourne JA: Immunohistochemical parcellation of the ferret (Mustela putorius) visual cortex reveals substantial homology with the cat (Felis catus). J Comp Neurol 2010, 518(21):4439-4462.

15. Buddington RK, Chen JW, Diamond JM: Dietary regulation of intestinal brush-border sugar and amino acid transport in carnivores. Am J Physiol 1991, 261(4 Pt 2):R793-801.

16. Arai T, Washizu T, Sako T, Sasaki M, Motoyoshi S: D-glucose transport activities in erythrocytes and hepatocytes of dogs, cats and cattle. Comp Biochem Physiol Comp Physiol 1992, 102(2):285-287.

17. Washizu T, Tanaka A, Sako T, Washizu M, Arai T: Comparison of the activities of enzymes related to glycolysis and gluconeogenesis in the liver of dogs and cats. Res Vet Sci 1999, 67(2):205-206.

18. Silva SV, Mercer JR: Effect of protein intake on amino acid catabolism and gluconeogenesis by isolated hepatocytes from the cat (Felis domestica). Comp Biochem Physiol B 1985, 80(3):603-607.

19. Kettelhut IC, Foss MC, Migliorini RH: Glucose homeostasis in a carnivorous animal (cat) and in rats fed a high-protein diet. Am J Physiol 1980, 239(5): R437-444.

20. Morris JH, Rogers QR: The metabolic basis for the taurine requirement of cats. Adv Exp Med Biol 1992, 315:33-44.

21. Morris JG: Nutritional and metabolic responses to arginine deficiency in carnivores. J Nutr 1985, 115(4):524-531.

22. Smalley KA, Rogers QR, Morris JG: Methionine requirement of kittens given amino acid diets containing adequate cystine. Br J Nutr 1983, 49(3):411-417.

23. Stewart PM, Batshaw M, Valle D, Walser M: Effects of arginine-free meals on ureagenesis in cats. Am J Physiol 1981, 241(4):E310-315.

24. Sturman JA, Gargano AD, Messing JM, Imaki H: Feline maternal taurine deficiency: effect on mother and offspring. J Nutr 1986, 116(4):655-667.

25. Chesney RW, Helms RA, Christensen M, Budreau AM, Han X, Sturman JA: The role of taurine in infant nutrition. Adv Exp Med Biol 1998, 442:463-476.

26. Morris JG: Idiosyncratic nutrient requirements of cats appear to be dietinduced evolutionary adaptations. Nutr Res Rev 2002, 15(1):153-168.

27. Pion PD, Kittleson MD, Thomas WP, Skiles ML, Rogers QR: Clinical findings in cats with dilated cardiomyopathy and relationship of findings to taurine deficiency. J Am Vet Med Assoc 1992, 201(2):267-274.

28. Schuller-Levis G, Mehta PD, Rudelli R, Sturman J: Immunologic consequences of taurine deficiency in cats. J Leukoc Biol 1990, 47(4):321-331.

29. Saransaari P, Oja SS: Taurine in the developing cat: uptake and release in different brain areas. Neurochem Res 1994, 19(1):77-82

30. Welles EG, Boudreaux MK, Tyler JW: Platelet, antithrombin, and fibrinolytic activities in taurine-deficient and taurine-replete cats. Am J Vet Res 1993, 54(8):1235-1243.

31. Buff S, Donze A, Guerin P, Guillaud J, Fontbonne A, Menezo Y: Taurine and hypotaurine in spermatozoa and epididymal fluid of cats. J Reprod Fertil Suppl 2001, 57:93-95 
32. Imaki H, Messing J, Sturman JA: Extensive taurine depletion and retina degeneration in cats treated with beta-alanine for 40 weeks. Adv Exp Med Biol 1998, 442:449-460.

33. Warskulat U, Heller-Stilb B, Oermann E, Zilles K, Haas H, Lang F, Haussinger D: Phenotype of the taurine transporter knockout mouse. Methods Enzymol 2007, 428:439-458

34. Pontius JU, Mullikin JC, Smith DR, Agencourt Sequencing Team, Lindblad Toh K, Gnerre S, Clamp M, Chang J, Stephens R, Neelam B, Volfovsky N, Schäffer AA, Agarwala R, Narfström K, Murphy WJ, Giger U, Roca AL, Antunes A, Menotti-Raymond M, Yuhki N, Pecon-Slattery J, Johnson WE, Bourque G, Tesler G, NISC Comparative Sequencing Program, O'Brien SJ: Initial sequence and comparative analysis of the cat genome. Genome Res 2007, 17(11):1675-1689.

35. Mullikin JC, Hansen NF, Shen L, Ebling H, Donahue WF, Tao W, Saranga DJ Brand A, Rubenfield MJ, Young AC, Cruz P, NISC Comparative Sequencing Program, Driscoll C, David V, Al-Murrani SW, Locniskar MF, Abrahamsen MS, O'Brien SJ, Smith DR, Brockman JA: Light whole genome sequence for SNP discovery across domestic cat breeds. BMC Genomics 2010, 11:406.

36. Flicek P, Amode MR, Barrell D, Beal K, Brent S, Chen Y, Clapham P, Coates G, Fairley S, Fitzgerald S, Gordon L, Hendrix M, Hourlier T, Johnson N, Kähäri A, Keefe D, Keenan S, Kinsella R, Kokocinski F, Kulesha E, Larsson P, Longden I, McLaren W, Overduin B, Pritchard B, Riat HS, Rios D, Ritchie GR, Ruffier M, Schuster M, et al: Ensembl 2011. Nucleic Acids Res 2011, , 39 Database: D800-806

37. Mortazavi A, Williams BA, McCue K, Schaeffer L, Wold B: Mapping and quantifying mammalian transcriptomes by RNA-Seq. Nat Methods 2008, 5(7):621-628.

38. Ramskold D, Wang ET, Burge CB, Sandberg R: An abundance of ubiquitously expressed genes revealed by tissue transcriptome sequence data. PLoS Comput Biol 2009, 5(12):e1000598.

39. Nielsen R: Statistical tests of selective neutrality in the age of genomics. Heredity 2001, 86(Pt 6):641-647.

40. Blake JA, Bult CJ, Eppig JT, Kadin JA, Richardson JE: The Mouse Genome Database genotypes:::phenotypes. Nucleic Acids Res 2009, , 37 Database: D712-719.

41. Yamaguti GG, Lourenco GJ, Silveira VS, Tone LG, Lopes LF, Lima CS: Increased risk for acute lymphoblastic leukemia in children with cytochrome P450A1 (CYP1A1)- and NAD(P)H:quinone oxidoreductase 1 (NQO1)-inherited gene variants. Acta Haematol 2010, 124(3):182-184

42. Strater J, Herter I, Merkel G, Hinz U, Weitz J, Moller P: Expression and prognostic significance of APAF-1, caspase- 8 and caspase- 9 in stage II/III colon carcinoma: caspase- 8 and caspase- 9 is associated with poor prognosis. Int J Cancer 2010, 127(4):873-880

43. Guo C, Ahmad T, Beckly J, Cummings JR, Hancock L, Geremia A, Cooney R, Pathan S, Jewell DP: Association of caspase-9 and RUNX3 with inflammatory bowel disease. Tissue Antigens 2011, 77(1):23-29.

44. Aubier M, Levy J, Clerici C, Neukirch F, Cabrieres F, Herman D: Protective effect of theophylline on bronchial hyperresponsiveness in patients with allergic rhinitis. The American review of respiratory disease 1991, 143(2):346-350.

45. Khor CC, Chapman SJ, Vannberg FO, Dunne A, Murphy C, Ling EY, Frodsham AJ, Walley AJ, Kyrieleis O, Khan A, Aucan C, Segal S, Moore CE, Knox K, Campbell SJ, Lienhardt C, Scott A, Aaby P, Sow OY, Grignani RT, Sillah J, Sirugo G, Peshu N, Williams TN, Maitland K, Davies RJ, Kwiatkowski DP, Day NP, Yala D, Crook DW, et al: A Mal functional variant is associated with protection against invasive pneumococcal disease, bacteremia, malaria and tuberculosis. Nat Genet 2007, 39(4):523-528.

46. Ginsberg JS, Caco CC, Brill-Edwards PA, Panju AA, Bona R, Demers CM, Tuters LM, Nugent P, McGinnis J, Grant BM: Venous thrombosis in patients who have undergone major hip or knee surgery: detection with compression US and impedance plethysmography. Radiology 1991, 181(3):651-654.

47. Franci C, Gallen M, Alameda F, Baro T, Iglesias M, Virtanen I, Garcia de Herreros A: Snail1 protein in the stroma as a new putative prognosis marker for colon tumours. PLoS One 2009, 4(5):e5595.

48. Peirson SN, Butler JN: RNA extraction from mammalian tissues. Methods Mol Biol 2007, 362:315-327.

49. Leshinsky-Silver E, Lebre AS, Minai L, Saada A, Steffann J, Cohen S, Rotig A, Munnich A, Lev D, Lerman-Sagie T: NDUFS4 mutations cause Leigh syndrome with predominant brainstem involvement. Mol Genet Metab 2009, 97(3):185-189.
50. Gatalica Z, Lele SM, Rampy BA, Norris BA: The expression of Fhit protein is related inversely to disease progression in patients with breast carcinoma. Cancer 2000, 88(6):1378-1383.

51. Jaeger PA, Wyss-Coray T: Beclin 1 complex in autophagy and Alzheimer disease. Archives of neurology 2010, 67(10):1181-1184.

52. Quintana A, Kruse SE, Kapur RP, Sanz E, Palmiter RD: Complex I deficiency due to loss of Ndufs4 in the brain results in progressive encephalopathy resembling Leigh syndrome. Proc Natl Acad Sci USA 2010, 107(24):10996-11001.

53. Abbott JA: Feline hypertrophic cardiomyopathy: an update. Vet Clin North Am Small Anim Pract 2010, 40(4):685-700.

54. Reddy S, Jia S, Geoffrey R, Lorier R, Suchi M, Broeckel U, Hessner MJ, Verbsky J: An autoinflammatory disease due to homozygous deletion of the IL1RN locus. The New England journal of medicine 2009, 360(23):2438-2444

55. Huang X, Bai HM, Chen L, Li B, Lu YC: Reduced expression of LC3B-II and Beclin 1 in glioblastoma multiforme indicates a down-regulated autophagic capacity that relates to the progression of astrocytic tumors. Journal of clinical neuroscience: official journal of the Neurosurgical Society of Australasia 2010, 17(12):1515-1519.

56. Koukourakis MI, Giatromanolaki A, Sivridis E, Pitiakoudis M, Gatter KC, Harris AL: Beclin 1 over- and underexpression in colorectal cancer: distinct patterns relate to prognosis and tumour hypoxia. British journal of cancer 2010, 103(8):1209-1214.

57. Hagen L, Pena-Diaz J, Kavli B, Otterlei M, Slupphaug G, Krokan HE: Genomic uracil and human disease. Experimental cell research 2006, 312(14):2666-2672

58. Oceandy D, Cartwright EJ, Neyses L: Ras-association domain family member 1A (RASSF1A)-where the heart and cancer meet. Trends in cardiovascular medicine 2009, 19(8):262-267.

59. Oceandy D, Pickard A, Prehar S, Zi M, Mohamed TM, Stanley PJ, BaudoinStanley F, Nadif R, Tommasi S, Pfeifer GP, Armesilla AL, Cartwright EJ, Neyses L: Tumor suppressor Ras-association domain family 1 isoform $A$ is a novel regulator of cardiac hypertrophy. Circulation 2009, 120(7):607-616.

60. Wilson HM: Feline alimentary lymphoma: demystifying the enigma. Top Companion Anim Med 2008, 23(4):177-184.

61. MySQL Relational Database Server. [http://www.mysql.com/]

62. Altschul SF, Madden TL, Schaffer AA, Zhang J, Zhang Z, Miller W, Lipman DJ: Gapped BLAST and PSI-BLAST: a new generation of protein database search programs. Nucleic Acids Res 1997, 25(17):3389-3402.

63. Basic Local Alignment Search Tool. [http://blast.ncbi.nlm.nih.gov/Blast.cgi].

64. Grasso C, Lee C: Combining partial order alignment and progressive multiple sequence alignment increases alignment speed and scalability to very large alignment problems. Bioinformatics 2004, 20(10):1546-1556.

65. Lee C, Grasso C, Sharlow MF: Multiple sequence alignment using partial order graphs. Bioinformatics 2002, 18(3):452-464.

66. Haider S, Ballester B, Smedley D, Zhang J, Rice P, Kasprzyk A: BioMart Central Portal-unified access to biological data. Nucleic Acids Res 2009, , 37 Web Server: W23-27.

67. Yang Z: PAML: a program package for phylogenetic analysis by maximum likelihood. Comput Appl Biosci 1997, 13(5):555-556.

68. Yang Z: PAML 4: phylogenetic analysis by maximum likelihood. $\mathrm{Mol}$ Biol Evol 2007, 24(8):1586-1591.

69. Suyama $M$, Torrents $D$, Bork P: PAL2NAL: robust conversion of protein sequence alignments into the corresponding codon alignments. Nucleic Acids Res 2006, 34 Web Server: W609-612.

70. Barrell D, Dimmer E, Huntley RP, Binns D, O'Donovan C, Apweiler R: The GOA database in 2009-an integrated Gene Ontology Annotation resource. Nucleic Acids Res 2009, 37 Database: D396-403.

71. Ogata H, Goto S, Fujibuchi W, Kanehisa M: Computation with the KEGG pathway database. Biosystems 1998, 47(1-2):119-128.

72. Mlecnik B, Scheideler M, Hackl H, Hartler J, Sanchez-Cabo F, Trajanoski Z: PathwayExplorer: web service for visualizing high-throughput expression data on biological pathways. Nucleic Acids Res 2005, , 33 Web Server: W633-637.

73. Sherman BT, Huang da W, Tan Q, Guo Y, Bour S, Liu D, Stephens R, Baseler MW, Lane HC, Lempicki RA: DAVID Knowledgebase: a genecentered database integrating heterogeneous gene annotation resources to facilitate high-throughput gene functional analysis. BMC Bioinformatics 2007, 8:426. 
74. Hamosh A, Scott AF, Amberger JS, Bocchini CA, McKusick VA: Online Mendelian Inheritance in Man (OMIM), a knowledgebase of human genes and genetic disorders. Nucleic Acids Res 2005, , 33 Database: D514-517.

75. Wang Y, Kelly MA, Cowan TM, Longo N: A missense mutation in the OCTN2 gene associated with residual carnitine transport activity. Human mutation 2000, 15(3):238-245.

76. D'Antonio KB, Toubaji A, Albadine R, Mondul AM, Platz EA, Netto GJ, Getzenberg $\mathrm{RH}$ : Extracellular matrix associated protein CYR61 is linked to prostate cancer development. The Journal of urology 2010, 183(4):1604-1610.

77. Arman A, Soylu O, Yildirim A, Furman A, Ercelen N, Aydogan H, Coker A, Tezel T: Interleukin-1 receptor antagonist gene VNTR polymorphism is associated with coronary artery disease. Arquivos brasileiros de cardiologia 2008, 91(5):293-298.

78. Di Domenico F, Sultana R, Tiu GF, Scheff NN, Perluigi M, Cini C, Butterfield DA: Protein levels of heat shock proteins 27, 32, 60, 70, 90 and thioredoxin-1 in amnestic mild cognitive impairment: an investigation on the role of cellular stress response in the progression of Alzheimer disease. Brain research 2010, 1333:72-81.

79. Lu CW, Lin JH, Rajawat YS, Jerng H, Rami TG, Sanchez X, DeFreitas G, Carabello B, DeMayo F, Kearney DL, Miller G, Li H, Pfaffinger PJ, Bowles NE, Khoury DS, Towbin JA, et al: Functional and clinical characterization of a mutation in KCNJ2 associated with Andersen-Tawil syndrome. Journal of medical genetics 2006, 43(8):653-659.

80. Priori SG, Pandit SV, Rivolta I, Berenfeld O, Ronchetti E, Dhamoon A, Napolitano C, Anumonwo J, di Barletta MR, Gudapakkam S, Bosi G, Stramba-Badiale M, Jalife J: A novel form of short QT syndrome (SQT3) is caused by a mutation in the KCNJ2 gene. Circulation research 2005, 96(7):800-807

81. Jacobson SG, Cideciyan AV, Aleman TS, Sumaroka A, Schwartz SB, Windsor EA, Roman AJ, Heon E, Stone EM, Thompson DA: RDH12 and RPE65, visual cycle genes causing leber congenital amaurosis, differ in disease expression. Investigative ophthalmology \& visual science 2007, 48(1):332-338.

82. Maruszak A, Safranow K, Gustaw K, Kijanowska-Haładyna B, Jakubowska K, Olszewska M, Styczyńska M, Berdyński M, Tysarowski A, Chlubek D, Siedlecki J, Barcikowska M, Zekanowski C: PIN1 gene variants in Alzheimer's disease. BMC medical genetics 2009, 10:115.

83. Barbaric D, Byth K, Dalla-Pozza L, Byrne JA: Expression of tumor protein D52-like genes in childhood leukemia at diagnosis: clinical and sample considerations. Leukemia research 2006, 30(11):1355-1363.

84. Wierzbicki PM, Adrych K, Kartanowicz D, Wypych J, Stanislawowski M, Zwolinska-Wcislo M, Celinski K, Skrodzka D, Godlewski J, Korybalski B, Smoczynski M, Kmiec Z: Overexpression of the fragile histidine triad (FHIT) gene in inflammatory bowel disease. Journal of physiology and pharmacology: an official journal of the Polish Physiological Society 2009, 60(Suppl 4):57-62.

85. Helmus Y, Denecke J, Yakubenia S, Robinson P, Luhn K, Watson DL, McGrogan PJ, Vestweber D, Marquardt T, Wild MK: Leukocyte adhesion deficiency II patients with a dual defect of the GDP-fucose transporter. Blood 2006, 107(10):3959-3966.

86. Zhao X, Graves C, Ames SJ, Fisher DE, Spanjaard RA: Mechanism of regulation and suppression of melanoma invasiveness by novel retinoic acid receptor-gamma target gene carbohydrate sulfotransferase 10 . Cancer research 2009, 69(12):5218-5225.

87. Hashimoto T, Nakai M: Increased hippocampal quinone reductase 2 in Alzheimer's disease. Neurosci Lett 2011, 502(1):10-12.

88. Cheng J, Zhu Y, He S, Lu Y, Chen J, Han B, Petrillo M, Wrzeszczynski KO, Yang S, Dai P, Zhai S, Han D, Zhang MQ, Li W, Liu X, Li H, Chen ZY, Yuan H: Functional mutation of SMAC/DIABLO, encoding a mitochondrial proapoptotic protein, causes human progressive hearing loss DFNA64. Am J Hum Genet 2011, 89(1):56-66.

89. Pluta P, Cebula-Obrzut B, Ehemann V, Pluta A, Wierzbowska A, Piekarski J, Bilski A, Nejc D, Kordek R, Robak T, Smolewski P, Jeziorski A: Correlation of Smac/DIABLO protein expression with the clinico-pathological features of breast cancer patients. Neoplasma 2011, 58(5):430-435.

doi:10.1186/1471-2164-13-31

Cite this article as: Irizarry et al.: Sequencing and comparative genomic analysis of 1227 Felis catus CDNA sequences enriched for developmental, clinical and nutritional phenotypes. BMC Genomics 2012 13:31.

\section{Submit your next manuscript to BioMed Central and take full advantage of:}

- Convenient online submission

- Thorough peer review

- No space constraints or color figure charges

- Immediate publication on acceptance

- Inclusion in PubMed, CAS, Scopus and Google Scholar

- Research which is freely available for redistribution

Submit your manuscript at www.biomedcentral.com/submit
C Biomed Central 